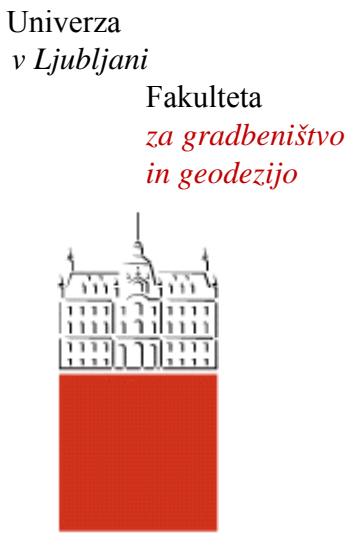

Jamova cesta 2

1000 Ljubljana, Slovenija

http://www3.fgg.uni-lj.si/

\section{DRUGG - Digitalni repozitorij UL FGG http://drugg.fgg.uni-lj.si/}

Ta članek je avtorjeva zadnja recenzirana različica, kot je bila sprejeta po opravljeni recenziji.

Prosimo, da se pri navajanju sklicujte na bibliografske podatke, kot je navedeno:
University
of Ljubljana

Faculty of

Civil and Geodetic

Engineering

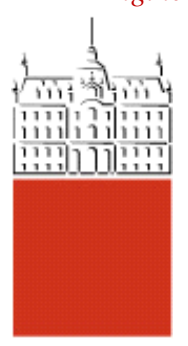

Jamova cesta 2

SI - 1000 Ljubljana, Slovenia

http://www3.fgg.uni-lj.si/en/

DRUGG - The Digital Repository
http://drugg.fgg.uni-lj.si/

This version of the article is author's manuscript as accepted for publishing after the review process.

When citing, please refer to the publisher's bibliographic information as follows:

Hozjan, T., Saje, M., Srpčič, S., Planinc, I. 2011. Fire analysis of steel-concrete composite beam with interlayer slip. Computers \& Structures 89,1-2: 189-200 DOI: 10.1016/j.compstruc.2010.09.004. 


\title{
Fire analysis of steel-concrete composite beam with interlayer slip
}

\author{
Tomaž Hozjan, Miran Saje, Stanislav Srpčič, Igor Planinc ${ }^{1}$ \\ University of Ljubljana, Faculty of Civil and Geodetic Engineering \\ Jamova 2, SI-1115 Ljubljana, Slovenia
}

\begin{abstract}
The paper discusses the effects of slip and moisture transfer on the behaviour of a planar steel-concrete composite beam subject to fire conditions. The moisture and heat transfer is assumed to be governed by a coupled problem, while the mechanical behaviour accounting for slip between layers is described by strain-based beam finite elements. Hence the fire analysis is perfomed in two separate steps, of which the moisture and heat transfer analysis is performed first, followed by the mechanical analysis. The present novel finite-element formulation proves itself perfect for the thermo-mechanical analysis of frame-like structures, as it is robust, reliable and accurate.
\end{abstract}

Keywords: steel-concrete composite beam, fire, slip between layers, moisture and heat transfer, high temperatures.

\footnotetext{
${ }^{1}$ Corresponding author. Phone.: +386 14768 616; fax: +386 14768629 .

E-mail address: iplaninc@fgg.uni-lj.si (I. Planinc)
} 


\section{Introduction}

Steel-concrete composite beams are often employed in office and industrial buildings or bridges and viaducts for fast and economic erection. Most usually they comprise a steel girder and a reinforced concrete slab interconnected by shear connectors (fasteners). The number of shear connectors largely determines whether the composite cross-section behaves as compact or partially connected. In any cases, the deformation of the beam causes some relative tangential displacement (slip) between the steel girder and the concrete slab. While usually being very small, slip can have a substantial effect on the overall ductility of the beam, which indicates that it should be taken into account in the analysis $[1,2,3,4]$. This seems to be particularly true when analysing behaviour of composite beams subject to extreme conditions including fire. Here we investigate the effect of slip on a planar, simply-supported composite beam subject to simultaneous action of mechanical loads and fire using a composite beam theory based on novel mechanical model of the structure.

Another issue that plays an important role in the concrete and composite steelconcrete beams response due to fire is the effect of moisture transport on the temperature and stress distribution histories in the concrete part of the corss-section. In the composite beam context discussed here, we are particularly interested in assessing these effects quantitatively. That is why an overview is given of the governing equations of the moisture and heat transfer along with definitions and descriptions of the related thermal and moisture data, and effects discussed in a numerical example. The model by Tenchev et al. [5] is implemented in the present work. It represents a substantially modified model previously proposed by Bažant and Thonguthai [6] and is now considered to be rather complete for the analysis of concrete structures in fire. It is represented by a system of coupled transient differential equations, governing heat and mass transfer and pore pressure development. We note that the model is only one among a few recent mathematical models of moisture and heat transfer in concrete at elevated temperatures proposed in literature, [7, 8, 9, 10].

Because the volumetric compressibility of water phase in concrete is much higher than 
the volumetric compressibility of concrete and thus the relative volume change of pore space cannot produce significant pressures in water [11], the moisture and heat transfer through concrete in fire can be considered independent of the mechanical deformation. Consequently, the hygro-thermo-mechanical analysis of the composite beam subject to simultaneous action of mechanical and fire loads can be perfomed in two separate steps; (i) analysing moisture and heat transfer first, and (ii) based on the moisture and heat transfer results, evaluating mechanical stresses and deformations. In the mechanical analysis, we assume that slip at the interface between the concrete and steel layers occurs, but the transverse separation (uplift) is not possible. An additive split of strain into thermal and mechanical parts is also assumed, where the creep strains including secondary and transient creep are considered to have their own contributions.

When the governing equations of the moisture and heat transfer, and of the mechanical behaviour of the composite beam are set, the fire analysis of engineering structures reduces to the mathematical problem of solving numerically the system of non-linear time-dependent differential equations of the first order, which is iteratively solved in space and time by the strain-based method of finite elements proposed recently by the authors. In the numerical example that follows, we test the validity of the present numerical model by comparing the results of our model with the data of experiment performed by Wainman and Kirby [12], and with the numerical results of Huang et al. [13] obtained by their original non-linear analysis procedures.

\section{Fire analysis of composite beam}

Fire initiates several time-dependent processes in a structure including heat and moisture transport and the redistribution of stresses. We may assume that these processes are sufficiently slow to admit the heat and moisture analysis to be performed as uncoupled with the stress analysis. This allows the fire analysis to be studied in two independent steps. The first step comprises the determination of the moisture, pore pressure and temperature fields in a composite beam subject to the given temperature regime in the fire compartment. This consists of solving in time simultaneously the differential equa- 
tions of heat conduction and of the Thenchev modified thermo-hydro-chemical model of moisture transport [5]. In the second step of the fire analysis, the stress and strain fields due to combined effects of mechanical and thermal loads are obtained. The two steps of the fire analysis are now presented in detail.

\subsection{First step of the fire analysis}

The increase of gas temperature in the fire compartment depends on many parameters and is therefore both a complex task to do and unreliable. That is why convenient, yet very much simplified parametric temperature-time curves for a number of typical situations have been introduced in engineering design practice long ago, which define explicit relationships between gas temperature in a compartment and time [14]. Once the variation of the gas temperature in the compartment with time has been defined, we determine moisture and temperature within the steel and concrete as a coupled problem, where temperatures, vapour pressure, free water, and mixture of dry air and water vapour content in concrete are treated as a coupled heat and moisture transfer. The model takes into account evaporation of free water, the liquefaction of water vapour and the dehydration of chemically bond water.

\subsubsection{Heat and mass transfer in concrete deck}

Following Tenchev et al. [5] the mathematical model of a coupled heat and moisture transfer in concrete exposed to fire is described with a system of mass conservation equations for each phase of concrete separately and with the energy conservation equation as

- Water conservation:

$$
\frac{\partial\left(\bar{\rho}_{L}\right)}{\partial t}=-\nabla \cdot \mathbf{J}_{L}-\dot{E}_{L}+\frac{\partial\left(\bar{\rho}_{D}\right)}{\partial t}
$$

- Water vapour conservation:

$$
\frac{\partial\left(\varepsilon_{G} \tilde{\rho}_{V}\right)}{\partial t}=-\nabla \cdot \mathbf{J}_{V}-\dot{E}_{L}
$$


- Air conservation:

$$
\frac{\partial\left(\varepsilon_{G} \tilde{\rho}_{A}\right)}{\partial t}=-\nabla \cdot \mathbf{J}_{A}
$$

○ Energy conservation:

$$
(\underline{\rho c}) \frac{\partial T}{\partial t}=-\nabla \cdot(-k \nabla T)-(\underline{\rho c \mathbf{v}}) \cdot \nabla T-\lambda_{E} \dot{E}_{L}-\lambda_{D} \frac{\partial\left(\bar{\rho}_{D}\right)}{\partial t} .
$$

In Eqs. (1)-(4) index $i \in\{L, V, A\}$ denotes the phases: $L$ is free water, $V$ is water vapour and $A$ is dry air; $\tilde{\rho}_{i}$ is the density of the phase $i ; \varepsilon_{G} \tilde{\rho}_{A}$ and $\varepsilon_{G} \tilde{\rho}_{V}$ are mass concentrations of air and water vapour per unit volume concrete; $\mathbf{J}_{i}$ is the mass flux of phase $i ; \dot{E}_{L}$ is the rate of evaporation of free water (including desorption); $\bar{\rho}_{L}$ is the mass of liquid water per unit volume of concrete; $t$ is time; $\nabla$ is the nabla operator; the dot between the vectors (e.g. $\mathbf{a} \cdot \mathbf{b}$ ) denotes the scalar product. In Eq. (4) $\underline{\rho c}$ is heat capacity of concrete, $k$ is thermal conductivity of concrete, $\underline{\rho c \mathbf{v}}$ relates to the energy transferred by the fluid flow, $\lambda_{E}$ is the specific heat of evaporation, $\lambda_{D}$ is specific heat of dehydration, $\bar{\rho}_{D}$ is the mass of bound water released by the dehydration per unit volume of concrete, and $T$ is the absolute temperature.

The mass fluxes of dry air, water vapour and free water can be expressed in terms of pressure and concentration gradients assuming that Darcy's and Fick's laws are applicable and that the diffusion of adsorbed water on the surface of the solid cement phase skeleton is negligible:

$$
\begin{gathered}
\mathbf{J}_{A}=\varepsilon_{G} \tilde{\rho}_{A} \mathbf{v}_{G}-\varepsilon_{G} \tilde{\rho}_{G} D_{A V} \nabla\left(\frac{\tilde{\rho}_{A}}{\tilde{\rho}_{G}}\right), \\
\mathbf{J}_{V}=\varepsilon_{G} \tilde{\rho}_{V} \mathbf{v}_{G}-\varepsilon_{G} \tilde{\rho}_{G} D_{V A} \nabla\left(\frac{\tilde{\rho}_{V}}{\tilde{\rho}_{G}}\right), \\
\mathbf{J}_{L}=\bar{\rho}_{L} \mathbf{v}_{L} .
\end{gathered}
$$

The fluxes are defined per unit area of concrete. In Eqs. (5)-(7), $D_{A V}$ and $D_{V A}$ are the diffusion coefficients of dry air in water vapour, and water vapour in dry air within the porous concrete, $\varepsilon_{G} \tilde{\rho}_{G}$ is the mass concentration of gas (mixture of dry air and water vapor), and $\mathbf{v}_{G}$ and $\mathbf{v}_{L}$ are the velocities of the gas and free water phases, respectively, resulting from a pressure-driven flow as given by Darcy's law:

$$
\mathbf{v}_{G}=\frac{K K_{G}}{\mu_{G}} \nabla P_{G}
$$




$$
\mathbf{v}_{L}=\frac{K K_{L}}{\mu_{L}} \nabla P_{L}
$$

Here $K$ is the intrinsic permeability of dry concrete, $K_{G}$ and $K_{L}$ are the relative permeabilities of the gas and the liquid phase, $\mu_{G}$ and $\mu_{L}$ are their dynamic viscosities, and $P_{G}$ and $P_{L}$ are the corresponding pressures. Following the model proposed by Tenchev et al. [5], it is here assumed that the liquid pressure is equal to the gas pressure, $P_{G}=P_{L}$. It is further assumed that air and water vapour behave as an ideal gas, and that the amount of free water $\bar{\rho}_{L}$ is determined with the help of sorption curves [11].

By summing Eqs. (1) and (2) we end up with three partial differential equations describing the transfer of dry air and moisture, and energy conservation. The solution is obtained numerically with the finite element method implemented in the course of the present research, where the primary unknowns of the moisture and heat transfer problem are temperature $T$, pore pressure $P_{G}$ and water vapour content $\tilde{\rho}_{V}$. For the detailed description of the numerical formulation, see Tenchev et al. [5].

\subsection{Second step of the fire analysis}

Once the temperature variation in time and space inside a structure during fire has been obtained, we start with the second step of the fire analysis in which we determine the stress-strain state in the steel-concrete composite beam. For each time interval $\left[t^{i-1}, t^{i}\right], i=1,2,3, \ldots$, employed previously in the heat and moisture transfer analysis, we determine iteratively the stress and strain state at time station $t^{i}$ based on a given mechanical results at $t^{i-1}$ and hygro-thermal results at $t^{i}$. Each material component (the layer) of the steel-concrete beam is modelled by its own beam using Reissner's beam theory [15], but with the effect of shear deformations being neglected. We also assume that only the tangential slip can occur at the interface between the two beams, and neglect any transverse separation (uplifts) between the components. The deformations and displacements of engineering structures at even accidential loadings are typically required to remain small. Hence the fracture of a structure should essentially be due to loss of the bearing capacity of material rather than due to very large displacements. That is why, in the present formulation, the geometrical non-linearity is neglected. The 
theoretically correct geometrically linear theory is obtained by the strict linearization of the geometrically exact Reissner's equations for each beam component around the initial undeformed configuration. As the relevant derivation has already been presented in [16], the details are here omitted. The stress-strain state in the steel-concrete composite beam is governed by (i) the system of kinematic, equilibrium and constitutive equations, combined with natural and essential boundary conditions for each layer, and (ii) by the equations of the contact between the layers.

\subsubsection{Kinematic, equilibrium and constitutive equations}

We consider an initially straight, planar, two-layer steel-concrete beam of undeformed length $L$. Layers shown in Fig. 1 are marked by letters $a$ and $b$. The slab is placed in $(X, Z)$ plane of the spatial Cartesian coordinate system with the coordinates $(X, Y, Z)$. Local coordinate systems $\left(x^{a}, y^{a}, z^{a}\right)$ and $\left(x^{b}, y^{b}, z^{b}\right)$ are assumed to coincide initially with the spatial coordinate system $(X, Y, Z)$. The steel-concrete beam is subjected

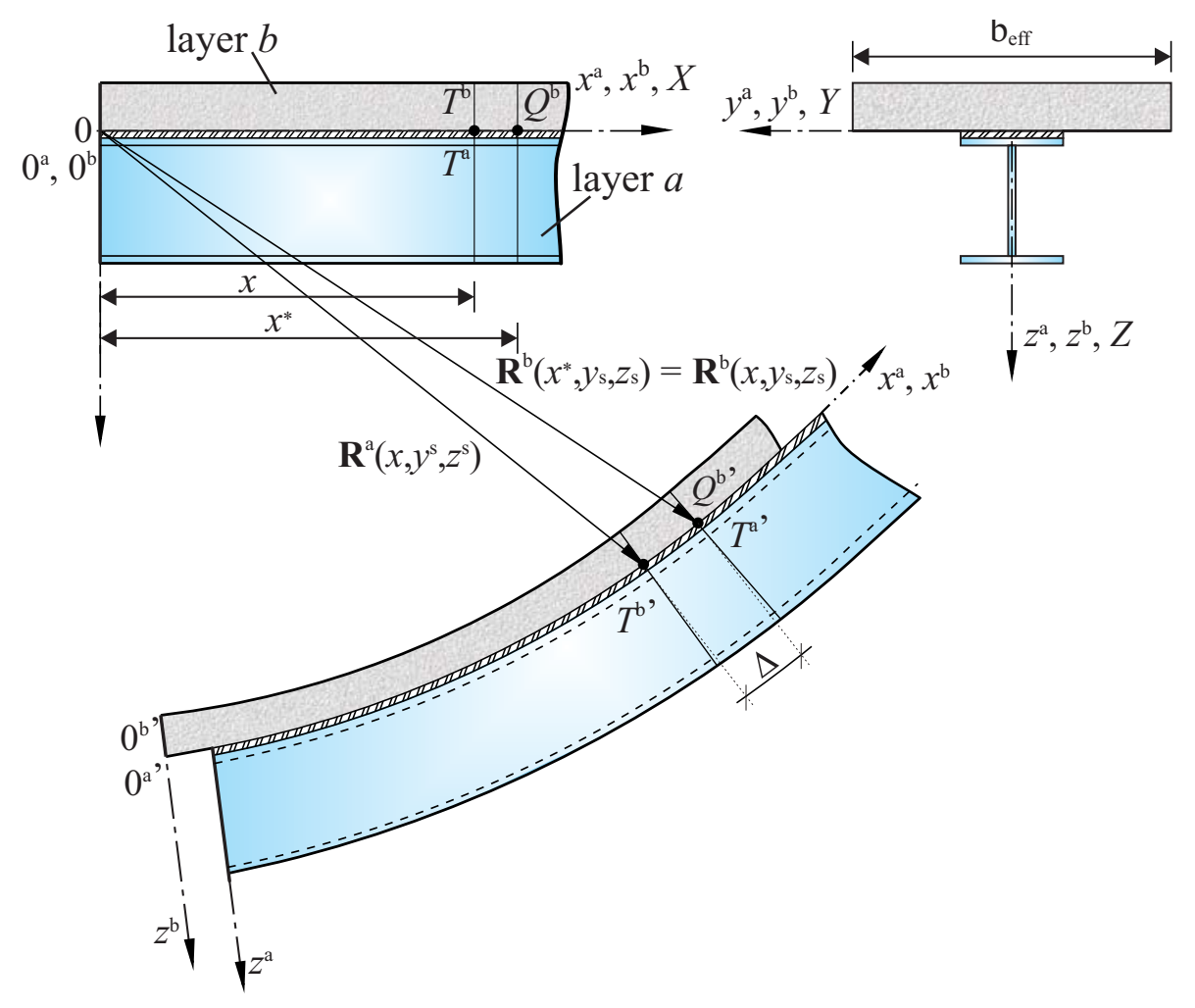

Fig. 1 Initial and deformed configuration of two-layer composite beam. 
to a conservative, time independent mechanical load, and a time-dependent growth of temperature over the cross-section; for further details, a reader is referred to [17]. The linearized kinematic equations of layers $a$ and $b$ are:

$$
\begin{aligned}
u^{a \prime}-\varepsilon=0, & u^{b \prime}-\varepsilon^{b}=0, \\
w^{a \prime}+\varphi^{a}=0, & w^{b \prime}+\varphi^{b}=0, \\
\varphi^{a \prime}-\kappa^{a}=0, & \varphi^{b \prime}-\kappa^{b}=0 .
\end{aligned}
$$

Here $(\cdot)^{\prime}$ denotes the derivative of $(\cdot)$ with respect to $x=x^{a}=x^{b} ; u^{a}$ and $w^{a}$ are the $X$ and $Z$ - components of the displacement vector of layer $a$. Similarly, the displacement components $u^{b}$ and $w^{b}$ belong to layer $b . \varphi^{a}$ and $\varphi^{b}$ are the cross-sectional rotation angles, $\varepsilon^{a}$ and $\varepsilon^{b}$ are the extensional strains (membrane deformations), and $\kappa^{a}$ and $\kappa^{b}$ are the curvatures (flexural deformations) of the reference axis of layers $a$ and $b$, respectively.

The equilibrium stress resultants at the cross-section, $\mathcal{N}^{i}, \mathcal{Q}^{i}, \mathcal{M}^{i}, i \in\{a, b\}$, are related to the distributed mechanical loads via equilibrium equations. The lower layer is unlikely to be exposed to the extra mechanical loads; therefore we take that only the upper layer is exposed to the external loads, i.e. $q_{X}=q_{X}^{b}, q_{Z}=q_{Z}^{b}, m_{Y}=m_{Y}^{b}$. After the linearization of the exact equilibrium equations is preformed [15], we end up with the following set of linear equilibrium equations:

$$
\begin{aligned}
\mathcal{N}^{a \prime}+p_{X}^{a}=0, & \mathcal{N}^{b \prime}+q_{X}+p_{X}^{b}=0, \\
\mathcal{Q}^{a \prime}+p_{Z}^{a}=0, & \mathcal{Q}^{b \prime}+q_{Z}+p_{Z}^{b}=0, \\
\mathcal{M}^{a \prime}-\mathcal{Q}^{a}=0, & \mathcal{M}^{b \prime}-\mathcal{Q}^{b}+m_{Y}=0,
\end{aligned}
$$

where $p_{X}^{a}, p_{X}^{b}, p_{Z}^{a}$ and $p_{Z}^{b}$ are the components of the contact traction vector.

The constitutive equations represent the last set of basic equations. They relate the equilibrium internal forces, $\mathcal{N}^{i}, \mathcal{M}^{i}, i \in\{a, b\}$, and the constitutive internal forces, $\mathcal{N}_{c}^{i}$, $\mathcal{M}_{c}^{i}, i \in\{a, b\}$, defined as the extensional stress resultants over the cross-section by

$$
\begin{array}{cc}
\mathcal{N}^{a}=\mathcal{N}_{c}^{a}=\int_{A^{a}} \sigma^{a}\left(D_{\sigma}^{a}\right) \mathrm{d} A, & \mathcal{N}^{b}=\mathcal{N}_{c}^{b}=\int_{A^{a}} \sigma^{b}\left(D_{\sigma}^{b}\right) \mathrm{d} A \\
\mathcal{M}^{a}=\mathcal{M}_{c}^{a}=\int_{A^{a}} z^{a} \sigma^{a}\left(D_{\sigma}^{a}\right) \mathrm{d} A, & \mathcal{M}^{b}=\mathcal{M}_{c}^{b}=\int_{A^{a}} z^{b} \sigma^{b}\left(D_{\sigma}^{b}\right) \mathrm{d} A .
\end{array}
$$


Here $D_{\sigma}^{a}$ and $D_{\sigma}^{b}$ are the mechanical extensional strains at a longitudinal fibre of layers $a$ or $b$, and the relationships $\sigma^{a}\left(D_{\sigma}^{a}\right)$ and $\sigma^{b}\left(D_{\sigma}^{b}\right)$ describe the stress-strain laws of layer materials. In the present study, the non-linear stress-strain relationships according to EC 2 [18] and EC 3 [19] are used for concrete, reinforcement bars and steel.

The related static and kinematic boundary conditions of the two layer composite beam consist of the boundary conditions for each individual layer. For layer $a$ they read

$$
x=0 \text { : }
$$

$$
\begin{aligned}
& \mathcal{N}^{a}(0)+S_{1}^{a}=0 \quad \text { or } \quad u^{a}(0)=u_{1}^{a}, \\
& \mathcal{Q}^{a}(0)+S_{2}^{a}=0 \quad \text { or } \quad w^{a}(0)=u_{2}^{a}, \\
& \mathcal{M}_{Z}^{a}(0)+S_{3}^{a}=0 \quad \text { or } \quad \varphi^{a}(0)=u_{3}^{a}, \\
& \mathcal{N}^{a}(L)-S_{4}^{a}=0 \quad \text { or } \quad u^{a}(L)=u_{4}^{a}, \\
& \mathcal{Q}^{a}(L)-S_{5}^{a}=0 \quad \text { or } \quad w^{a}(L)=u_{5}^{a}, \\
& \mathcal{M}_{Z}^{a}(L)-S_{6}^{a}=0 \quad \text { or } \quad \varphi^{a}(L)=u_{6}^{a} \text {. }
\end{aligned}
$$

Similar expressions hold for layer $b$. In Eqs. (18)-(23), $u_{i}^{a}(i=1, \ldots, 6)$ mark the given values of the boundary displacements, and $S_{i}^{a}(i=1, \ldots, 6)$ are the given forces at the edges of layer $a$.

\subsubsection{Constraining equations}

It is assumed that the two layers slip over each other but do not separate. This is mathematically described by the condition of conformity of the radius vectors of the currently connecting points of the contact surfaces as

$$
\boldsymbol{R}^{a}(x)=\boldsymbol{R}^{b}\left(x^{*}\right)
$$

or in the componential form,

$$
\begin{aligned}
x+u^{a}(x) & =x^{*}+u^{b}\left(x^{*}\right), \\
w^{a}(x) & =w^{b}\left(x^{*}\right),
\end{aligned}
$$

where $x^{*}$ represents an undeformed coordinate of that particular material point of layer $b$ which, in the deformed state, gets in contact with the material point of layer $a$ having 
$x$ as the initial undeformed coordinate. The slip between the two points in the deformed configuration that coincide in the undeformed shape is denoted by $\Delta$. It is defined as the difference of the lengths of the deformed contacting lines of layers $a$ and $b$ :

$$
\Delta(x)=\Delta(0)+s^{a}-s^{b},
$$

where

$$
\begin{aligned}
& s^{a}=\int_{0}^{T^{a \prime}}\left(1+D^{a}(x)\right) \mathrm{d} x, \\
& s^{b}=\int_{0}^{T^{b^{\prime}}}\left(1+D^{b}(x)\right) \mathrm{d} x .
\end{aligned}
$$

$\Delta(0)$ is slip between the two points at $x=0 . D^{a}$ and $D^{b}$ are the so called geometric extensional strains of the contacting fibres of layers $a$ and $b$. Since Bernoulli's hypothesis is assumed, the extensional strain of a beam fibre is defined as

$$
D(x, z)=\varepsilon(x)+z \kappa(x) .
$$

Once the $z$-coordinate of the contacting fibre is inserted into (30), the appropriate expressions $D^{a}$ and $D^{b}$ of layers $a$ and $b$ are obtained. For a geometrically linear composite beam theory, the initial slip $\Delta(0)$ is obtained from the given initial displacements as $\Delta(0)=u^{a}(0)-u^{b}(0)$. It appears that the differentiated form

$$
\Delta^{\prime}(x)=\varepsilon^{a}(x)-\varepsilon^{b}(x)
$$

is more convenient for the numerical formulation compared to the one given in Eq. (27). Hence Eq. (31) rather than Eq. (27) is used in the finite element implementation.

We assume that slip between the layers is realized in a fictitious layer of thickness zero. After the mechanical loading and/or temperature has increased and slip taken place and if we adopt that $\operatorname{slip} \Delta(x)$ is small, the traction at point $x$ of layers $a$ and $b$ is equal, i.e. according to the action-reaction law, both the normal, $p_{n}^{i}$, and the tangential, $p_{t}^{i}, i=a, b$, traction components must satisfy the equilibrium equations:

$$
\begin{aligned}
p_{n}^{a}(x)+p_{n}^{b}(x) & =0 \\
p_{t}^{a}(x)+p_{t}^{b}(x) & =0
\end{aligned}
$$


Since we have assumed that deformations, displacements and slip are small quantities, Eqs. (32) and (33) transformed into the $(X, Y, Z)$-system result in

$$
\begin{aligned}
& p_{X}^{a}(x)=-p_{X}^{b}(x)=p_{t}^{a}(x)=-p_{t}^{b}(x)=p_{t}(x), \\
& p_{Z}^{a}(x)=-p_{Z}^{b}(x)=p_{n}^{a}(x)=-p_{n}^{b}(x)=p_{n}(x) .
\end{aligned}
$$

In general, the flexibility of the contact highly depends both on materials involved and the way the contact between the layers is designed. Since no uplift between the layers is allowed, we only have to introduce the constitutive law for the tangential traction force as:

$$
p_{t}(x)=\mathcal{G}\left(\Delta, T, p_{n}, \ldots\right),
$$

with $\mathcal{G}$ being an arbitrary non-linear function. The law (36) is in engineering literature called the 'shear flow-slip relation'.

\subsubsection{Principle of additivity of strains}

Based on the given stress and strain at time $t^{i-1}$ and the given temperatures at $t^{i}>t^{i-1}$ and at $t^{i-1}$, we wish to determine the unknown extensional strains $D^{a}$ and $D^{b}$ in layers $a$ and $b$ at time $t^{i}$ of any point of the steel-concrete beam using incremental equations

$$
\begin{aligned}
& D^{a, i}=D^{a, i-1}+\Delta D^{a, i}, \\
& D^{b, i}=D^{b, i-1}+\Delta D^{b, i}
\end{aligned}
$$

where $\Delta D^{a, i}$ and $\Delta D^{b, i}$ are the increments of the geometrical strains in the time interval $\left[t^{i-1}, t^{i}\right]$. Invoking the principle of additivity of strains $[20,21]$ and the nature of material models of concrete and steel at elevated temperatures, we propose that the geometrical strain increment in a point, $\Delta D^{i}$, is the sum of the strain increments due to the change of temperature, $\Delta D_{t h}^{i}$, stress, $\Delta D_{\sigma}^{i}$, and creep, $\Delta D_{c r}^{i}$, and, for concrete only, of the transient strain increment, $\Delta D_{t r}^{i}$ :

$$
\begin{aligned}
\text { steel: } & \Delta D^{a, i}=\Delta D_{t h}^{a, i}+\Delta D_{\sigma}^{a, i}+\Delta D_{c r}^{a, i} \\
\text { concrete: } & \Delta D^{b, i}=\Delta D_{t h}^{b, i}+\Delta D_{\sigma}^{b, i}+\Delta D_{c r}^{b, i}+\Delta D_{t r}^{b, i} .
\end{aligned}
$$


The temperature strain increment $\Delta D_{t h}^{i}$ as a function of temperature is described by Eurocode 3 [19] for the steel part of the composite beam, $D_{t h}^{a, i}$, and by Eurocode 2 [18] for the concrete deck, $D_{t h}^{b, i}$. There the total, $D_{t h}^{i}$, rather than the incremental temperature strain, $\Delta D_{t h}^{i}$, is given with a formal expression $D_{t h}^{i}=\mathcal{H}\left(T^{i}\right)$. The thermal strain increment in time step $\left[t^{i-1}, t^{i}\right]$ is thus determined by the equation $\Delta D_{t h}^{i}=\mathcal{H}\left(T^{i}\right)-\mathcal{H}\left(T^{i-1}\right)=$ $D_{t h}^{i}-D_{t h}^{i-1}$.

The mechanical strain increment, $\Delta D_{\sigma}^{i}$, is assumed to combine the elastic and plastic parts, $\Delta D_{\sigma}^{i}=\Delta D_{\sigma, e}^{i}+\Delta D_{\sigma, p}^{i}$. We further assume that the relationship between the extensional stress, and the mechanical extensional strain is given in the functional form dependent both on strain and temperature, $\sigma=\mathcal{F}\left(D_{\sigma}, T\right)$, where $\mathcal{F}$ is the constitutive functional to be determined experimentally for the chosen material. In the present analysis, we use the standardized laws for steel and concrete at elevated temperatures from EC3 [19] and EC2 [18]. Thus, in the time step $\left[t^{i-1}, t^{i}\right]$, the stress increment $\Delta \sigma^{i}$ at a material point is given by the relation $\Delta \sigma^{i}=\sigma^{i}-\sigma^{i-1}=\mathcal{F}\left(D_{\sigma}^{i}, T^{i}\right)-\mathcal{F}\left(D_{\sigma}^{i-1}, T^{i-1}\right)$.

The creep strain increment of steel, $\Delta D_{c r}^{a, i}$ is, in general, a function of the current temperature, stress, time and the total accumulated creep strain $D_{c r}^{a, i}[20]$. In experiments, however, it is very difficult to separate, in a unique and accurate way, mechanical and creep parts of the strain at high temperature. That is why the creep strain of steel is in most formulations treated as being combined with the plastic (i.e. mechanical) strain into an overall, time independent inelastic strain. An example of such a material model, where creep strains are considered a constitutive part of the overall inelastic strains is the material model of steel at elevated temperatures of EC3 [19]. Consequently, the increment of the creep strain no longer explicitly takes place in the addition principle (39), i.e. $\Delta D_{c r}^{a, i}=0$.

The creep strain of concrete, $D_{c r}^{b}$, also highly depends on the current stress, time and temperature. The model that well considers these parameters, was proposed by Harmathy [22]:

$$
D_{\mathrm{cr}, \mathrm{c}}^{i}=\beta_{1} \frac{\sigma_{\mathrm{c}}^{i}}{f_{\mathrm{c}, T}^{i}} \sqrt{t^{i}} \mathrm{e}^{d\left(T^{i}-293\right)} .
$$

Here, $f_{\mathrm{c}, T}^{i}>0$ is the strength of concrete at temperature $T^{i}[K]$ (taken as a positive number), $t^{i}[\mathrm{~s}]$ is time and $\beta_{1}$ and $d$ are empirical constants of material. In our subsequent 
numerical studies, we take values proposed by Bratina et al. [23]: $\beta_{1}=6.28 \cdot 10^{-6}$, $d=2.658 \cdot 10^{-3} \mathrm{~K}^{-1}$. The creep strain increment of concrete in the time step $\left[t^{i-1}, t^{i}\right]$ is then given by the equation: $\Delta D_{c r}^{b, i}=D_{c r}^{b, i}-D_{c r}^{b, i-1}$.

The increment of the transient strain in concrete, $\Delta D_{t r}^{b, i}$, has been formulated by Anderberg and Thelandersson [24], among others, and is also assumed in the present study. It is defined by

$$
\Delta D_{t r}^{b, i}=\left\{\begin{array}{ll}
k_{2} \frac{\sigma_{\mathrm{c}}^{i}}{f_{\mathrm{c} 0}} \Delta D_{t h}^{b, i} ; & T \leq 550{ }^{\circ} \mathrm{C} \\
0.01 \frac{\sigma_{\mathrm{c}}^{i}}{f_{\mathrm{c} 0}} ; & T>550{ }^{\circ} \mathrm{C}
\end{array},\right.
$$

where $f_{\mathrm{c} 0}>0$ is strength of concrete at room temperature, and $k_{2}$ is a dimensionless constant whose range is $1.8 \leq k_{2} \leq 2.35$ [24]. It is noted that $\Delta D_{t r}^{b, i}$ and $\Delta D_{t h}^{b, i}$ have opposite signs if stress, $\sigma_{\mathrm{c}}^{i}$, is compressive and $\Delta T>0$.

\subsubsection{Basic equations of a composite beam with an interlayer slip}

After linearizing Eqs. (25) and (26) around the initial undeformed configuration $(\varphi=0)$ and employing the derived results in Eqs. (10)-(12), we obtain [17]:

$$
\begin{aligned}
x^{*} & =x+\Delta, \\
w^{a} & =w^{b}=w, \\
\varphi^{a} & =\varphi^{b}=\varphi, \\
\kappa^{a} & =\kappa^{b}=\kappa,
\end{aligned}
$$

where $w, \varphi$ and $\kappa$ are the deflection, rotation and bending strain of the reference axis of the composite beam. The resulting Eqs. (44)-(46) reduce the number of unknowns and simplify the kinematic equations (11) and (12) of the composite beam substantially, yieding the equations:

$$
\begin{aligned}
& \varphi=-w^{\prime}, \\
& \kappa=\varphi^{\prime}=-w^{\prime \prime} .
\end{aligned}
$$

In the same manner, the equilibrium equations of layers $a$ and $b$ are easily reformulated into the linearized equilibrium equations of the composite beam. To that end we introduce the total equilibrium shear force of the composite beam, $\mathcal{Q}$, defined as the sum of 
the equilibrium shear forces of layers $a$ and $b: \mathcal{Q}=\mathcal{Q}^{a}+\mathcal{Q}^{b}$. After adding Eq. (14) and considering Eq. (35), we obtain

$$
\mathcal{Q}^{\prime}+q_{Z}=0
$$

Similarly, from the moment equilibrium Eq. (15), we derive

$$
\mathcal{M}^{\prime}-\mathcal{Q}+m_{Y}=0
$$

where $\mathcal{M}=\mathcal{M}^{a}+\mathcal{M}^{b}$ is the total equilibrium bending moment of the composite beam. With these findings, our final system of the differential and algebraic equations of the composite beam is conveniently written by the two sets of equations

$$
\begin{gathered}
u^{a \prime}-\varepsilon^{a}=0, \\
u^{b \prime}-\varepsilon^{b}=0, \\
w^{\prime}+\varphi=0, \\
\varphi^{\prime}-\kappa=0, \\
\mathcal{N}^{a \prime}+p_{t}=0, \\
\mathcal{N}^{b \prime}-p_{t}+q_{X}=0, \\
\mathcal{Q}^{\prime}+q_{Z}=0, \\
\mathcal{M}^{\prime}-\mathcal{Q}+m_{Y}=0, \\
\mathcal{N}^{a}-\mathcal{N}_{c}^{a}=0, \\
\mathcal{N}^{b}-\mathcal{N}_{c}^{b}=0, \\
\mathcal{M}-\mathcal{M}_{c}=0, \\
\Delta_{t}^{\prime}=\varepsilon^{a}-\varepsilon^{b}, \\
\mathcal{G}\left(\Delta, T, p_{n}, \ldots\right),
\end{gathered}
$$


and

$$
\begin{aligned}
x^{*} & =x+\Delta, \\
\mathcal{Q} & =\mathcal{Q}^{a}+\mathcal{Q}^{b}, \\
\mathcal{M} & =\mathcal{M}^{a}+\mathcal{M}^{b}, \\
\mathcal{Q}^{a \prime}+p_{n} & =0 \text { or } \mathcal{Q}^{b \prime}-p_{n}+q_{Z}=0, \\
\mathcal{M}^{a \prime}-\mathcal{Q}^{a} & =0 \text { or } \mathcal{M}^{b \prime}-\mathcal{Q}^{b}+m_{Y}=0, \\
\mathcal{M}^{a} & =\mathcal{M}_{c}^{a} \text { or } \mathcal{M}^{b}=\mathcal{M}_{c}^{b}
\end{aligned}
$$

along with the appropriate boundary conditions. The system of Eqs. (51)-(64) represents the governing system of differential and algebraic equations of the composite beam. It consists of thirteen equations for thirteen essential unknown fuctions of $x: \varepsilon^{a}, \varepsilon^{b}, \kappa, u^{a}$, $u^{b}, w, \varphi, \mathcal{N}^{a}, \mathcal{N}^{b}, \mathcal{Q}, \mathcal{M}, \Delta$ and $p_{t}$. After Eqs. (51)-(64) have been solved, the solution for $\Delta, \mathcal{Q}, \mathcal{M}$ is inserted into Eqs. (65)-(70) and solved for six remaining unknown functions of $x: x^{*}, \mathcal{Q}^{a}, \mathcal{Q}^{b}, \mathcal{M}^{a}, \mathcal{M}^{b}, p_{n}$.

\subsubsection{The finite element formulation}

Due to non-linear constitutive relationships, no analytical solution can be found for the boundary-value problem (51)-(64), so that we have to resort to numerical methods of solution. Here we use the Galerkin-type of the collocational finite element method to determine the stress-strain state in the composite beam [25, 26]. Extensional strains, $\varepsilon^{a}, \varepsilon^{b}$, and the bending strain, $\kappa$, rather than the displacements as is the tradition are approximated by a standard polynomial interpolation scheme:

$$
\begin{aligned}
\varepsilon^{a} & =\sum_{n=1}^{N} P_{n} \varepsilon_{n}^{a}, \\
\varepsilon^{b} & =\sum_{n=1}^{N} P_{n} \varepsilon_{n}^{b}, \\
\kappa & =\sum_{n=1}^{N} P_{n} \kappa_{n},
\end{aligned}
$$

where $N$ is the number of equidistant interpolation points $\left(x_{1}=0, x_{1}=\frac{L}{N-1}, \ldots, x_{N}=\right.$ $L), \varepsilon_{n}^{a}, \varepsilon_{n}^{b}$ and $\kappa_{n}$ are values of the extensional and bending strains in interpolation points, 
and $P_{n}$ are Lagrangian polynomials of order $N-1$. After employing interpolations (71)-(73) in the generalized principle of virtual work [26], we obtain the following EulerLagrange equations of the composite beam at time $t^{i}$ :

$$
\begin{aligned}
& g_{n \varepsilon^{a}}^{i}=\int_{0}^{L}\left(\mathcal{N}^{a, i}-\mathcal{N}_{\mathrm{c}}^{a, i}\right) P_{n} \mathrm{~d} \xi=0, \quad n=1, \ldots, N \\
& g_{N+n \varepsilon^{b}}^{i}=\int_{0}^{L}\left(\mathcal{N}^{b, i}-\mathcal{N}_{\mathrm{c}}^{b, i}\right) P_{n} \mathrm{~d} \xi=0, \quad n=1, \ldots, N \\
& g_{2 N+n \kappa}^{i}=\int_{0}^{L}\left(\mathcal{M}^{i}-\mathcal{M}_{\mathrm{c}}^{i}\right) P_{n} \mathrm{~d} \xi=0, \quad n=1, \ldots, N \\
& g_{3 N+1}^{i}=u^{a, i}(L)-u^{a, i}(0)-\left(P_{1}(L) \varepsilon_{1}^{a, i}+P_{2}(L) \varepsilon_{2}^{a, i}+\ldots+P_{N}(L) \varepsilon_{N}^{a, i}\right)=0, \\
& g_{3 N+2}^{i}=u^{b, i}(L)-u^{b, i}(0)-\left(P_{1}(L) \varepsilon_{1}^{b, i}+P_{2}(L) \varepsilon_{2}^{b, i}+\ldots+P_{N}(L) \varepsilon_{N}^{b, i}\right)=0, \\
& g_{3 N+3}^{i}=w^{i}(L)-w^{i}(0)+\rho^{i}(0) x+\left(I P_{1}(L) \kappa_{1}^{i}+I P_{2}(L) \kappa_{2}^{i}+\ldots+I P_{N}(L) \kappa_{N}^{i}\right)=0, \\
& g_{3 N+4}^{i}=\varphi^{i}(L)-\varphi^{i}(0)-\left(P_{1}(L) \kappa_{1}^{i}+P_{2}(L) \kappa_{2}^{i}+\ldots+P_{N}(L) \kappa_{N}^{i}\right)=0, \\
& g_{3 N+5}^{i}=\mathcal{N}^{a, i}(0)+S_{1}^{a}=0, \\
& g_{3 N+6}^{i}=\mathcal{N}^{b, i}(0)+S_{1}^{b}=0, \\
& g_{3 N+7}^{i}=\mathcal{Q}^{i}(0)+S_{2}=0, \\
& g_{3 N+8}^{i}=\mathcal{M}^{i}(0)+S_{3}=0, \\
& g_{3 N+9}^{i}=\mathcal{N}_{X}^{a, i}(0)-S_{4}^{a}-\int_{0}^{L} p_{t}^{i}(\xi) \mathrm{d} \xi=0, \\
& g_{3 N+10}^{i}=\mathcal{N}_{X}^{b, i}(0)-S_{4}^{b}-\int_{0}^{L} q_{X}(\xi)+p_{t}^{i}(\xi) \mathrm{d} \xi=0, \\
& g_{3 N+11}^{i}=\mathcal{Q}^{i}(0)-S_{5}-\int_{0}^{L} q_{Z}(\xi) \mathrm{d} \xi=0, \\
& g_{3 N+12}^{i}=\mathcal{M}^{i}(0)-S_{6}+\int_{0}^{L}\left(\mathcal{Q}(\xi)-m_{Y}(\xi)\right) \mathrm{d} \xi=0,
\end{aligned}
$$

where index $i$ denotes that the symbol is computed at time $t^{i}$ and index $j$ that is evaluated at interpolation point $j ; \varepsilon_{j}^{a, i}, \varepsilon_{j}^{b, i}$ and $\kappa_{j}^{i}(j=1,2, \ldots, N)$ are the values of $\varepsilon^{a}, \varepsilon^{b}$ and $\kappa$ at $t^{i} ; P_{j}=\int_{0}^{x} L_{j}(\xi) \mathrm{d} \xi$ and $I P_{j}=\int_{0}^{x} P_{j}(\xi) \mathrm{d} \xi$ are the integrals of the $j$-th Lagrangian polynomial. Eqs. (74)-(88) constitute a system of $3 N+12$ non-linear algebraic equations 
for $3 N+12$ unknowns. There are $3 N+4$ internal unknowns (degrees of freedom), $\varepsilon_{j}^{a, i}, \varepsilon_{j}^{b, i}$, $\kappa_{j}^{i},(j=1,2, \ldots, N), \mathcal{N}^{a, i}(0), \mathcal{N}^{b, i}(0), \mathcal{Q}^{i}(0)$ and $\mathcal{M}^{i}(0)$, and eight external unknowns (degrees of freedom) representing the boundary displacements and rotations of the finite element, i.e. $u^{a, i}(0), u^{b, i}(0), w^{i}(0), \varphi^{i}(0), u^{a, i}(L), u^{b, i}(L), w^{i}(L)$ and $\varphi^{i}(L)$. For the sake of conveniency of computation, the internal degrees of freedom are condensed before assembling the element equations into the global system of the discretized equations of the structure to obtain:

$$
\mathbf{G}\left(\mathbf{x}^{i}, \lambda^{i}, T^{i}, t^{i}\right)=0 .
$$

In (89) index $i$ denotes the time step at $t^{i}, \mathbf{x}^{i}$ is the column vector of the external unknowns with respect to the global coordinate system, $\lambda^{i}$ is the mechanical load factor and $T^{i}$ is the temperature. It is solved iteratively by Newton's method. The iterative corrections of the unknowns of the problem, $\delta \mathbf{x}^{i}$, are determined from the solution of the linearized Eq. (89)

$$
\nabla_{x} \mathbf{G}\left(\mathbf{x}^{i-1}+\Delta \mathbf{x}_{k}^{i}, \lambda^{i}, T^{i}, t^{i}\right) \delta \mathbf{x}_{k+i}^{i}=-\mathbf{G}\left(\mathbf{x}^{i-1}+\Delta \mathbf{x}_{k}^{i}, \lambda^{i}, T^{i}, t^{i}\right),
$$

provided that the tangent stiffnes matrix, $\nabla_{x} \mathbf{G} \equiv \mathbf{K}_{T, k}^{i}$, is not singular. The corrected incremental displacements are obtained by the addition as

$$
\Delta \mathbf{x}_{k+1}^{i}=\Delta \mathbf{x}_{k}^{i}+\delta \mathbf{x}_{k+i}^{i}
$$

where $k=1,2, \ldots$ presents the counter of iterations. The iteration is completed once a sufficient accuracy of $\mathbf{x}^{i}$ is achieved. If the tangent stiffness matrix becomes singular, $\operatorname{det} \mathbf{K}_{T, k}^{i}=0$, or if the displacements start increasing rapidly, the structure reaches or approaches its ultimate (critical) bearing capacity. The related time and temperature are termed the 'critical time' and the 'critical temperature' of the structure. Note that the singularity of the tangent stiffness matrix indicates the global instability of a structure. The option that a local, strain-softening instability at a cross-section takes place during fire is also possible and is here defined as the state at which the determinant of the tangent constitutive matrix of a cross-section becomes zero [27]. The practical capacity of the present thermo-hydro-mechanical numerical procedure for the analysis of behaviour of composite beams exposed to fire is presented next. 


\section{Numerical example}

In our numerical example, we study a simply supported, steel-concrete beam, simultaneously exposed to mechanical and thermal loads simulating fire conditions. Numerical results are verified with the experimental data [12] and compared with the numerical results [13]. Two different levels of mechanical loads are considered in fire analyses. The corresponding cases are marked as $\mathrm{S}_{1}$ and $\mathrm{S}_{2}$.

\subsection{Thermal and moisture analysis of composite beam}

Fig. 2 presents the relevant data of the steel-concrete, simply supported beam: geometry, loading, reinforcement and the finite element mesh over the cross-section employed in the calculations of heat and moisture fields. The composite cross-section is modelled with 516 four-node isoparametric quadrilateral finite elements; 460 finite elements are used for modelling the concrete part of the cross-section, and 56 finite elements for modelling the steel part. The thermal load simulating fire conditions is described by the standard fire curve ISO 834 [28]. Due to the symmetry of the cross-section with respect to axis

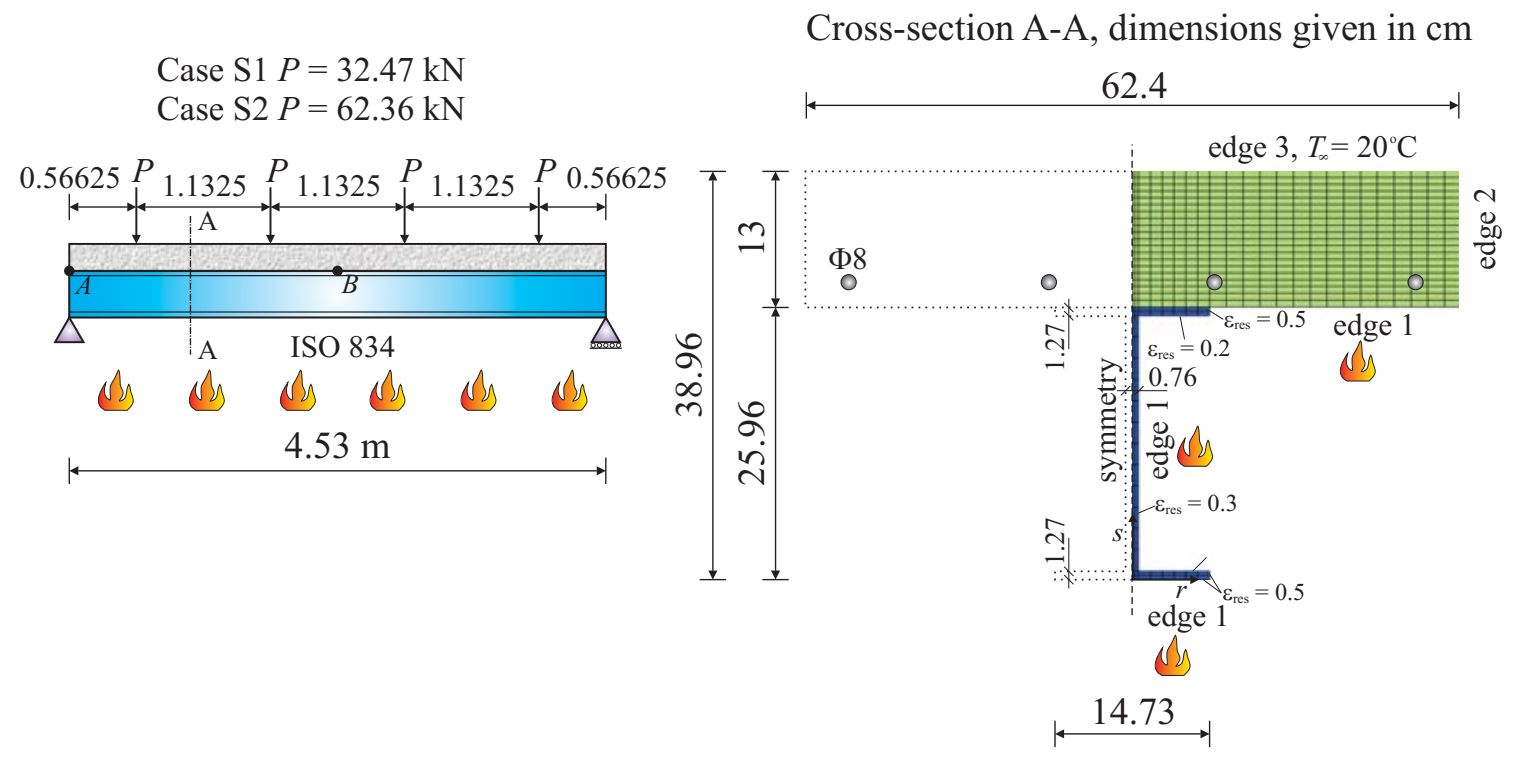

Fig. 2 Simply supported composite beam.

$z$, only one half is analysed with the assumption of the zero flow of moisture and heat across the symmetry axis. Different emissivities, $\varepsilon_{\text {res }}$, along the individual surfaces of the 
steel I-profile are used as suggested in [29]; they are depicted in Fig. 2. The emissivity over the concrete surface is taken to be $\varepsilon_{\text {res }}=0.6$. The convection factor also varies, and is assumed according to standards EC 2 [18] and EC $3[19]$ to be $h_{q}=25 \mathrm{~W} / \mathrm{m}^{2} \mathrm{~K}$ for the fire exposed surfaces (edges 1 and 2) for both steel and concrete. On the unexposed edge 3, we neglect radiation but consider the heat flux due to cold air convection with the convection factor taken as $h_{q}=9 \mathrm{~W} / \mathrm{m}^{2} \mathrm{~K}$. In performing the diffusion analysis, the connection between steel and concrete has been considered perfect during fire. At the contact between steel and concrete, the heat flux is permitted but the moisture flux is prevented due to the impervious steel surface and the perfect contact resulting in the zero gradient of pore pressure and vapour content. Consequently, the vapour cannot escape through the boundary between steel and concrete. The remaining data are [5]: density of concrete $\rho_{\mathrm{c}}=2400 \mathrm{~kg} / \mathrm{m}^{3}$, density of cement $\rho_{\text {cem }}=300 \mathrm{~kg} / \mathrm{m}^{3}$, initial temperature $T_{0}=20^{\circ} \mathrm{C}$, initial pore pressure $P_{G, 0}=0.1 \mathrm{MPa}$, initial water vapour content $\tilde{\rho}_{V, 0}=0.013 \mathrm{~kg} / \mathrm{m}^{3}$, water vapour content on boundary $\tilde{\rho}_{V, \infty}=0.0104 \mathrm{~kg} / \mathrm{m}^{3}$, initial porosity of concrete $p_{o r}^{0}=0.15$, initial permeability of concrete $K=1 \cdot 10^{-16}$ and initial free water amount $\bar{\rho}_{F W}^{0}=10 \mathrm{~kg} / \mathrm{m}^{3}$. The boundary conditions are summarized in Table 1.

Table 1 Boundary conditions for composite beam.

\begin{tabular}{|c|c|c|c|c|}
\hline & edge 1 & $\begin{array}{c}\text { edge } 2 \text { and } \\
\text { symmetry axis }\end{array}$ & edge 3 & $\begin{array}{c}\text { steel-concrete } \\
\text { contact }\end{array}$ \\
\hline$T$ & $\mathrm{q}_{T}=\mathrm{q}_{T}\left(T_{\mathrm{ISO} 834}\right)$ & $\frac{\partial T}{\partial n}=0$ & $\mathrm{q}_{T}=\mathrm{q}_{T}\left(T_{\infty}=20^{\circ} \mathrm{C}\right)$ & $\mathrm{q}_{T, \mathrm{c}}=\mathrm{q}_{T, \mathrm{~s}}$ \\
\hline$P_{G}$ & $P_{G}=0.1 \mathrm{MPa}$ & $\frac{\partial P_{G}}{\partial n}=0$ & $P_{G}=0.1 \mathrm{MPa}$ & $\frac{\partial P_{G}}{\partial n}=0$ \\
\hline$\tilde{\rho}_{V}$ & $\mathrm{q}_{V}=\mathrm{q}_{V}\left(\tilde{\rho}_{V, \infty}\right)$ & $\frac{\partial \tilde{\rho}_{V}}{\partial n}=0$ & $\mathrm{q}_{V}=\mathrm{q}_{V}\left(\tilde{\rho}_{V, \infty}\right)$ & $\frac{\partial \tilde{\rho}_{V}}{\partial n}=0$ \\
\hline
\end{tabular}

The distribution of temperature over the cross-section of the composite beam at 10, 30 and $60 \mathrm{~min}$ is presented in Fig. 3. As expected the results show that the rate of increase in temperature of the steel beam is much higher than that of the concrete slab. This is 
due to a higher thermal conductivity and a lower specific heat of steel. We also notice that the temperature in the top flange and in the upper part of the web of the steel profile is lower compared to the bottom part. This is due to the heat flow from the steel beam to the less hot concrete slab. The temperature difference between the bottom
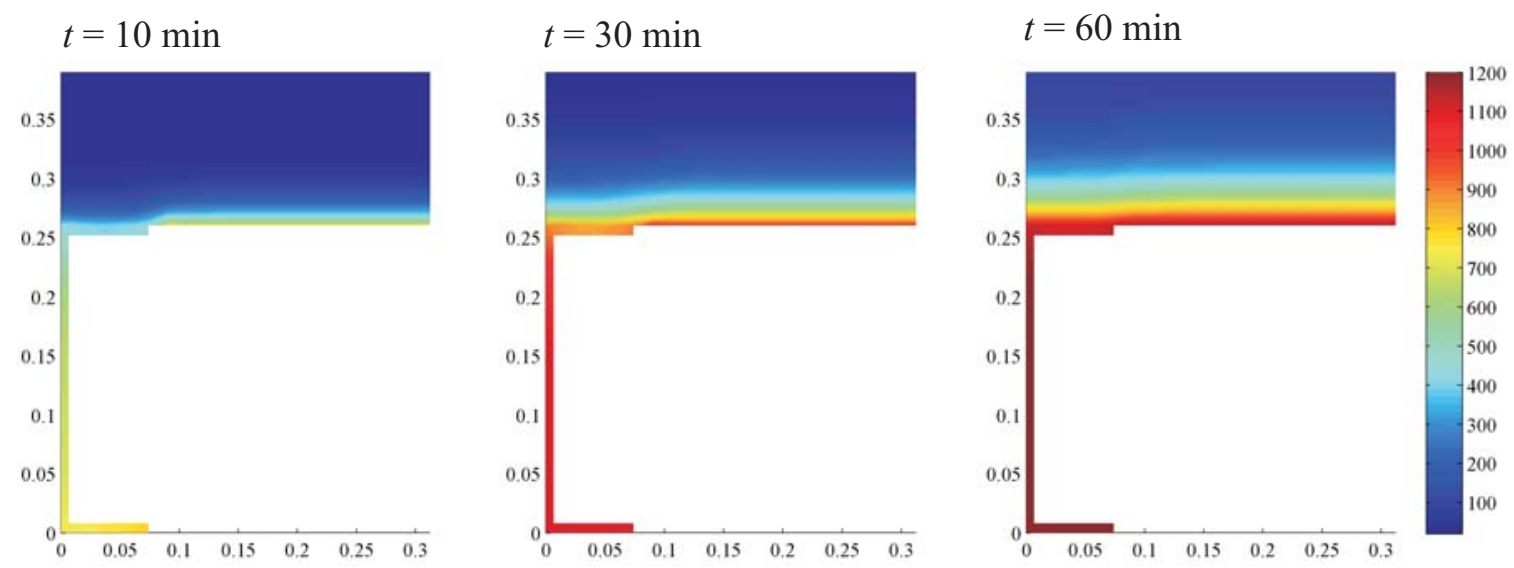

Fig. 3 Distribution of temperature (in ${ }^{\circ} \mathrm{C}$ ) over the cross-section at 10,30 and $60 \mathrm{~min}$.

and the top flange appears to be as high as about $50 \%$ after 10 minutes of fire and about $30 \%$ after 30 minutes; then it decreases and amounts to about $9 \%$ at 90 minutes. This is further made clear in Fig. 4, where the time development of temperatures in characteristic points of the cross-section is presented. The exact positions of points A, B, C and D are numerically described in Table 2 and marked in the cross-section graph inserted in Fig. 4. After 60 minutes have passed, the temperatures in points A and B

Table 2 Coordinates of points A, B, C and D.

\begin{tabular}{ccc} 
točka & $r[\mathrm{~cm}]$ & $s[\mathrm{~cm}]$ \\
\hline A & 4 & 0 \\
B & 0.63 & 12.98 \\
C & 4 & 25.96 \\
D & 4 & 28.56
\end{tabular}

almost coincide, while the temperature in point $\mathrm{C}$ still lags behind. We can see that the 


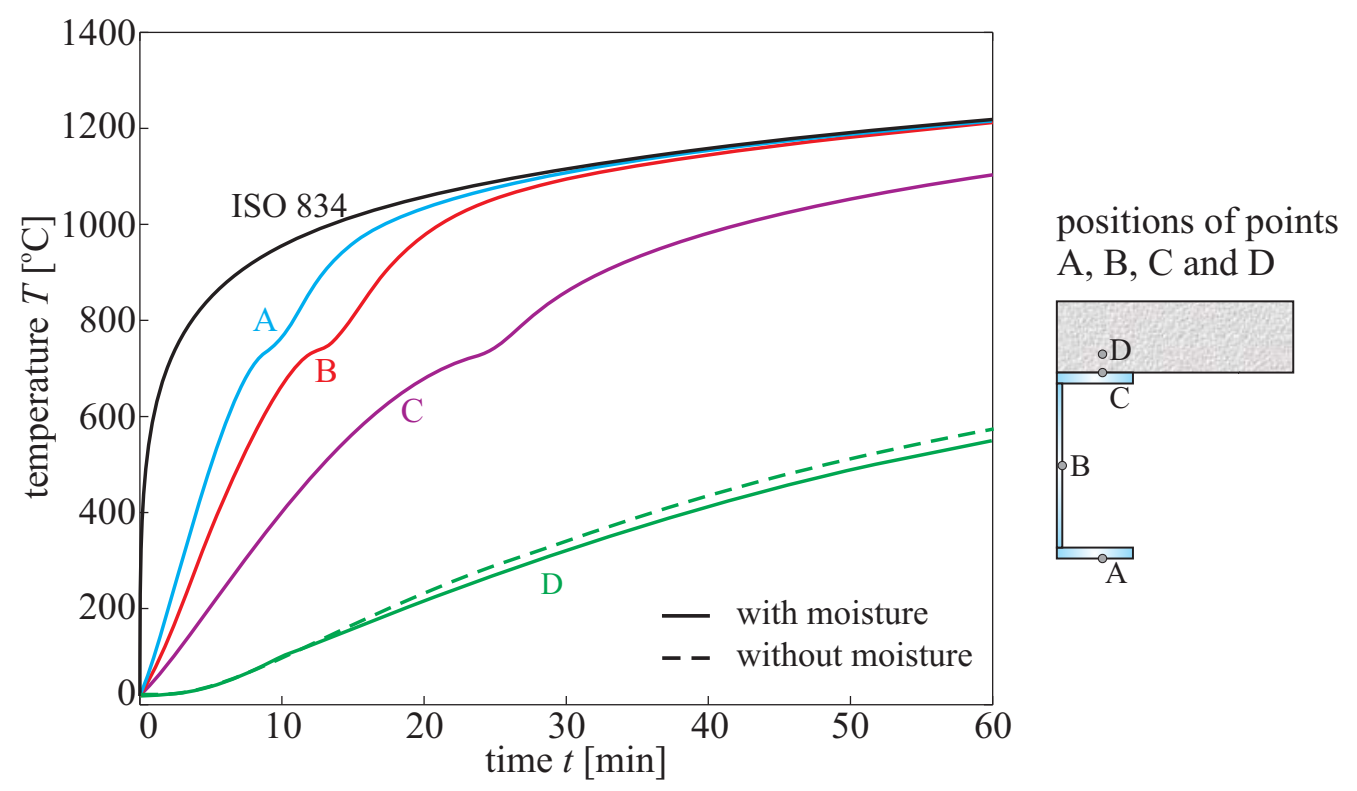

Fig. 4 The increase of temperature in points A, B, C and D with time.

high heat capacity of the concrete deck has a favourable effect of much slowing down the rate of increase of temperature in the top flange of the steel beam, particularly during an earlier phase of the fire. This may somewhat enhance the bearing capacity of the steel beam, prolong its critical time and improve the overall fire safety of the composite beam. On the other hand, the temperature gradient over the height of the steel section is substantially larger, resulting in an enhaced bending moment. Which of the two phenomena dominates depends on the combination of material, geometrical and loading data. It is well known that the heat diffusion in concrete is much slower compared to steel. This is again demonstrated in the present case, where the temperature in point D, situated only $2.5 \mathrm{~cm}$ away from the external edge exposed to fire, is only around $500^{\circ} \mathrm{C}$ at 60 min, which is roughly $50 \%$ of the corresponding temperature in points $\mathrm{A}$ and $\mathrm{B}$ of the steel girder. As observed in Fig. 4, a short-lasting temperature delay takes place at points $\mathrm{A}, \mathrm{B}$ and $\mathrm{C}$ at around $730^{\circ} \mathrm{C}$. This phenomenon is a consequence of the sudden local increase of the specific heat of steel at $735^{\circ} \mathrm{C}$ [19], see Fig 5. For comparison an additional analysis with programme HeatC [30] has also been carried out, which considers only the heat transfer while neglecting any mass transfer. Results for the temperature are presented with the dashed line in Fig. 4. It is somewhat surprising that the effect 
of the simultaneous moisture and vapour transport on the concrete temperature is not significant. In fact, the temperature at concrete point $\mathrm{D}$ is enhanced only for about $30^{\circ} \mathrm{C}$ at 60 min. The temperatures in points $\mathrm{A}, \mathrm{B}$ and $\mathrm{C}$ of the steel beam are not affected at all.

(a) specific heat of steel

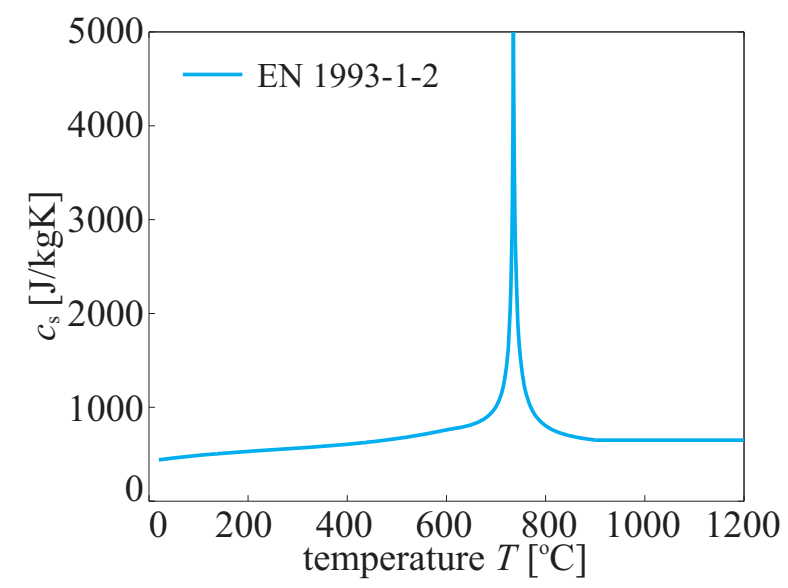

(b) specific heat of concrete

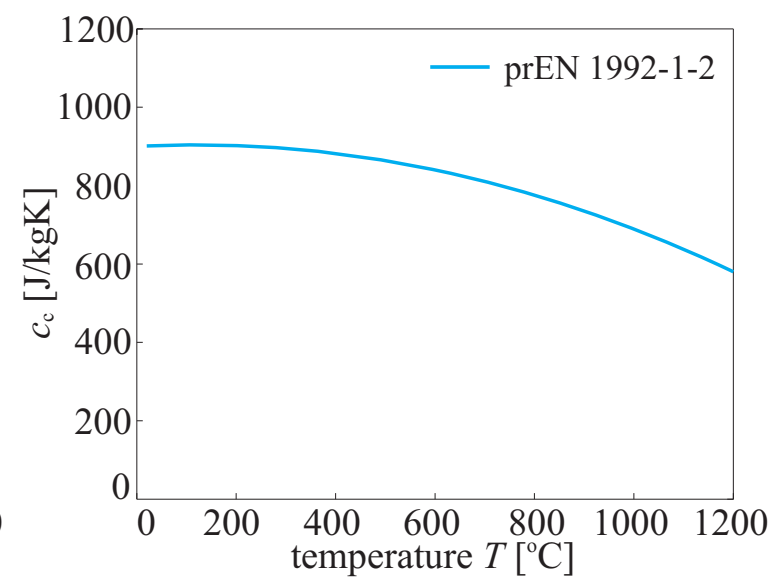

Fig. 5 Specific heat as a function of temperature for (a) steel; (b) concrete.

Figs. $6 \mathrm{a}$ and $6 \mathrm{~b}$ show the distributions of pore pressure and free water content over the cross-section at significant instants. As observed from the figures, the increase of moisture density (the free water content) is maximal at the contact between the steel beam and the concrete slab. The high concentration of the free water results in a simultaneous increase of pore pressures (Fig. 6a). The moisture, captured inside the concrete slab, follows the rise of temperature to partly change into vapour while being driven by the high-pressurized vapour towards the top edge (edge 3), where it eventually escapes out. After $60 \mathrm{~min}$ of fire have passed, about one half of the concrete section is dry, see Fig 6b. The increased pore pressure zone spreads between the steel-concrete contact and the increased free water front (Fig. 6a); the region outside the free water front is humid as initially (Fig. 6b). The zone of the high pore pressures extends with the increase of temperature and tends to spread over the whole concrete section. In contrast, the zone of free water looks much like a single wave front moving upwards. It is now clear that the high pore pressure in concrete is also due to the impervious steel-concrete contact. Figs. 3 and 6 show the results for temperatures, pore pressures and free water at various 
(a) pore pressure $P_{G}[\mathrm{Mpa}]$
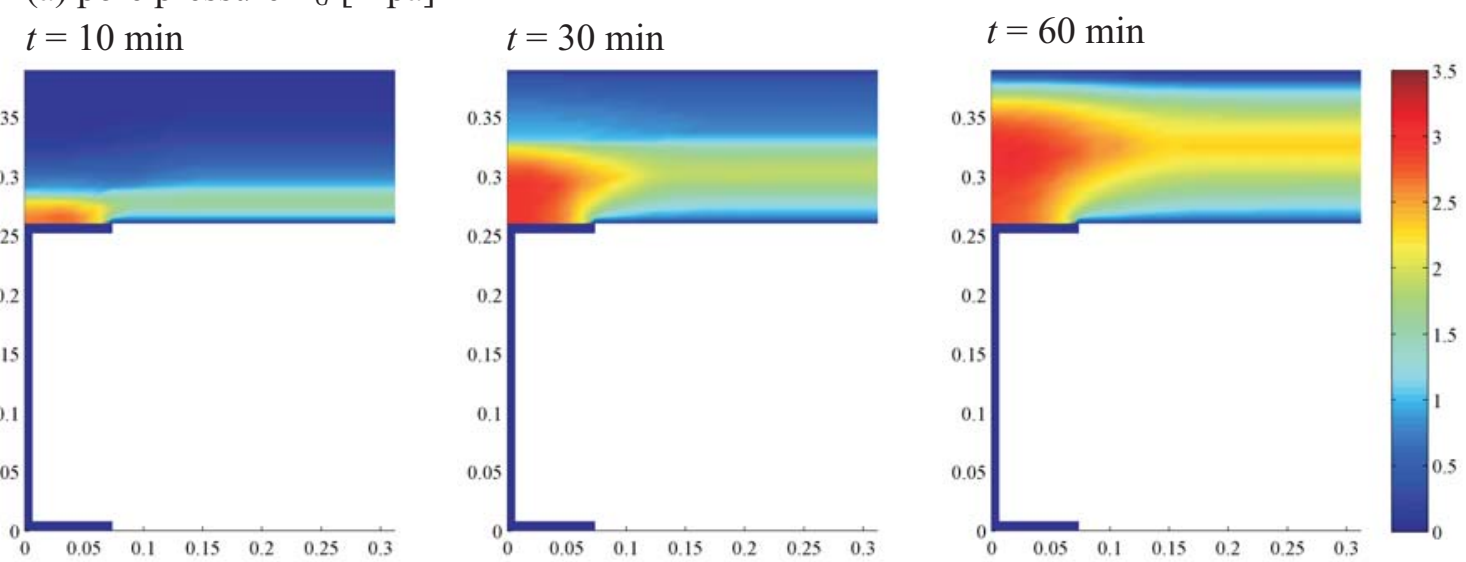

(b) free water content $\bar{\rho}_{F W}\left[\mathrm{~kg} / \mathrm{m}^{3}\right]$
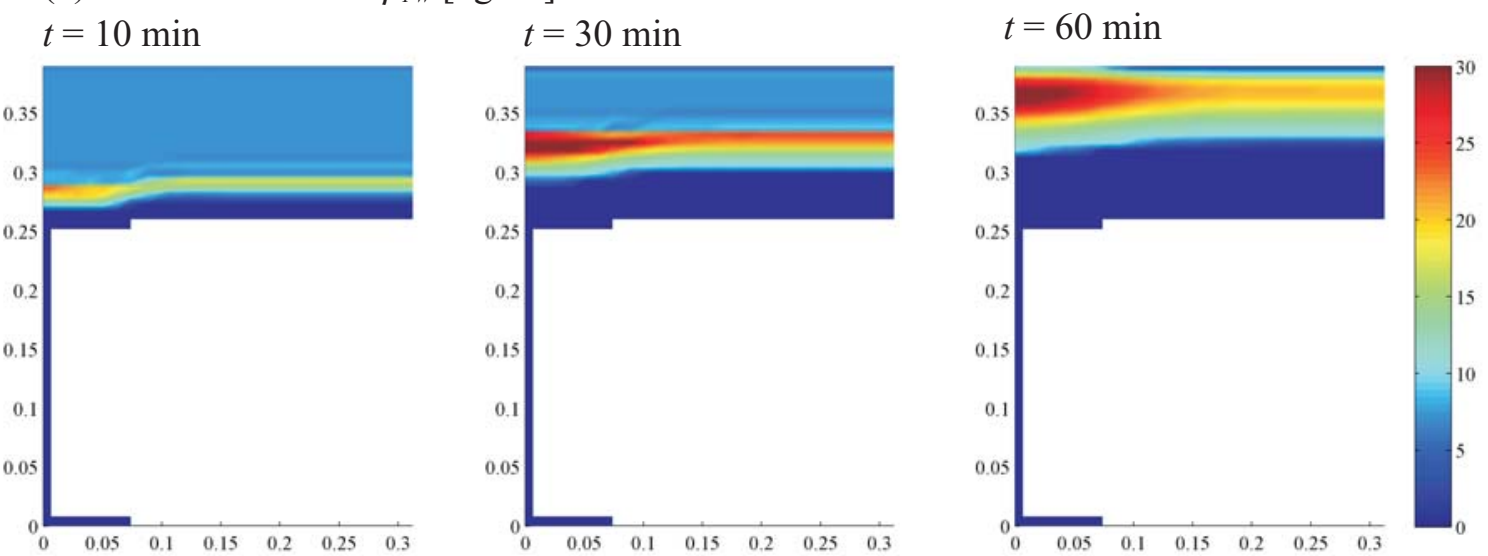

Fig. 6 (a) Distribution of pore pressure over the cross-section at the selected times. (b) Distribution of the free water content over the cross-section at the selected times.

discrete instants. According to these results, the maximal temperature of the steel girder at $60 \mathrm{~min}$ of fire is about $1100{ }^{\circ} \mathrm{C}$. It is not reasonable to expect that the composite beam is able to sustain such a high temperature. The heat and moisture analysis itself, however, cannot offer the critical time of the ultimate bearing capacity. The critical time will be estimated only in the next section, where the mechanical analysis is performed based on the temperature distributions shown above.

\subsection{Mechanical analysis of composite beam}

Next we present the mechanical analysis of a 4.53 meter long composite beam displayed in Fig. 2. The results of the previous section for the distribution of the temperature over 
the typical cross-section of the composite beam with time were used as the thermal load. It is assumed that the heat transfer in the axial direction of the beam is small and can be neglected. We study two cases both having an equal temperature regime, but performed at different external load levels, $P_{1}=34.47 \mathrm{kN}$, and $P_{2}=62.36 \mathrm{kN}$. Geometrical data of the beam and the details regarding the load and reinforcement arrangements are depicted in Fig. 2. The finite-element mesh of the beam model consists of 8 finite elements of the fifth order polynomials for the interpolation of strains. For the axial integration, Lobatto's 5-point scheme is used. The absolute error for Newton's iterative scheme was $1 \cdot 10^{-7}$. Typically 5 iterations were required to reach the above given tolerance if the time step in the mechanical analysis was equal to $1 \mathrm{~min}$.

The verification of the present numerical formulation is made by comparing the present numerical results with the data reported in the experiment by Wainman and Kirby [12] and the numerical results reported in Huang et al. [13]. The nominal values of the material data at ambient temperature reported by Wainman and Kirby [12] are: compressive strength of concrete $f_{\mathrm{c}, 20}=3 \mathrm{kN} / \mathrm{cm}^{2}$, yield strength of steel $f_{\mathrm{ys}, 20}=$ $25.5 \mathrm{kN} / \mathrm{cm}^{2}$, yield strength of reinforcing steel $f_{\mathrm{ya}, 20}=60 \mathrm{kN} / \mathrm{cm}^{2}$ and ultimate shear strength steel for fasteners is $f_{\mathrm{u}, 20}=35 \mathrm{kN} / \mathrm{cm}^{2}$. The stress-strain relationship for steel at elevated temperatures is taken from standard Eurocode 3 [19]. In this material model, the creep strain of steel at elevated temperatures is combined with the plastic strain into an overall inelastic strain as discussed in Sec. 2.3 and is thus only implicitly considered. The stress-strain relationship at elevated temperatures for concrete and reinforcing steel is assumed to follow another standard [18]. The numerical values of parameters for the normal weight concrete made from siliceous aggregate at elevated temperatures are also taken from these standards.

No experimental data of the temperatures within the shear studs were available. The estimate of Huang et al. [13] that their temperature was roughly $75 \%$ of that at the top of the upper flange, is also employed here. The beam is designed to have 32 shear studs, placed uniformly over the length of the composite beam. The constitutive law of contact of Huang et al. [13] is used, in which the maximal bearing capacity of a shear stud per length of the centroidal axis at room temperature is $p_{t, \max }=7 \mathrm{kN} / \mathrm{cm}$. 
The essential results of the mechanical analyses are summarized in Figs. 7-10. Fig. 7 shows the increase of the midspan deflection with temperature of the bottom flange for cases S1 and S2. The present numerical results are compared with the experimental data

(a) case $\mathrm{S} 1$

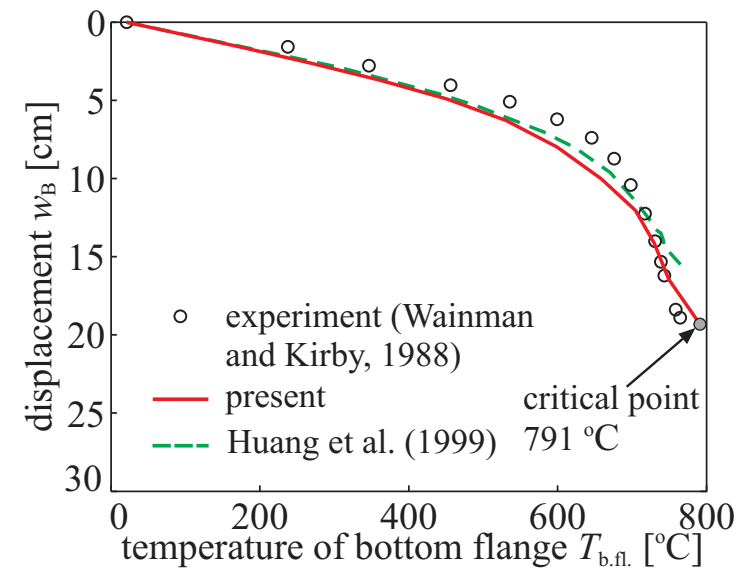

(b) case $\mathrm{S} 2$

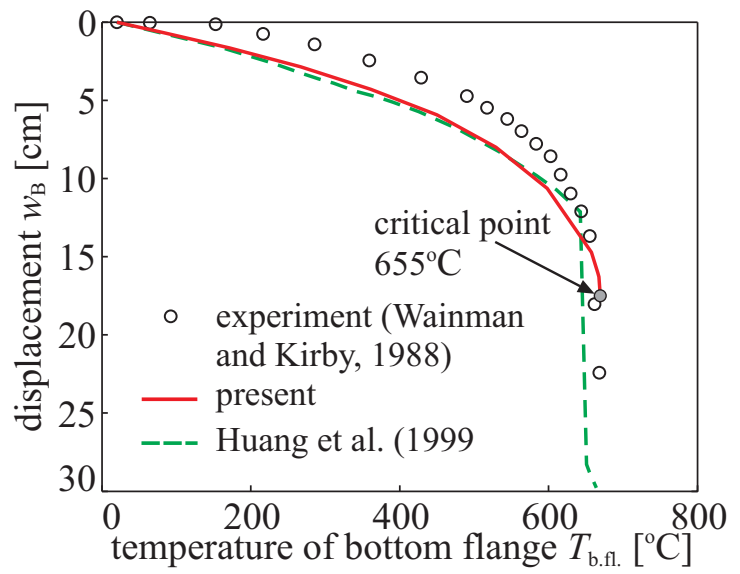

Fig. 7 The variation of the midspan deflection with temperature. (a) case S1; (b) case S2.

[12], and with the numerical results [13]. It is clear that the agreement with both the experimental and the numerical data is good. Note, in particular, a very good agreement in the critical temperature.

In both cases, $\mathrm{S} 1$ and $\mathrm{S} 2$, failure of the composite beam as predicted by the present formulation takes place due to failure of the composite cross-section. Prior to failure, a material instability was observed in the concrete part of the cross-section, yielding shortly after to the material instability of the composite cross-section. As observed from Fig. 7, the rapid increase of the midspan deflection starts at about $700^{\circ} \mathrm{C}$ (case S1) and $650^{\circ} \mathrm{C}$ (case S2), leading to the failure of the critical cross-section. In contrast Wainman and Kirby [12] reported that failure occurred due to fracture of the shear studs. As already mentioned, failure temperatures agree well with those in experiment which are roughly $780^{\circ} \mathrm{C}$ and $670^{\circ} \mathrm{C}$ in cases $\mathrm{S} 1$ and $\mathrm{S} 2$, respectively. The computed critical deflections also agree well with the measured ones.

Slip in the steel-concrete contact is depicted in Fig. 8 for three selected temperatures $T_{\text {b.fl. }}$ of the bottom flange. As expected, the distribution of slip is antisymmetric with respect to the midpoint $x=\frac{L}{2}$. This is due to the perfect symmetry of the load, 
(a) case $\mathrm{S} 1$

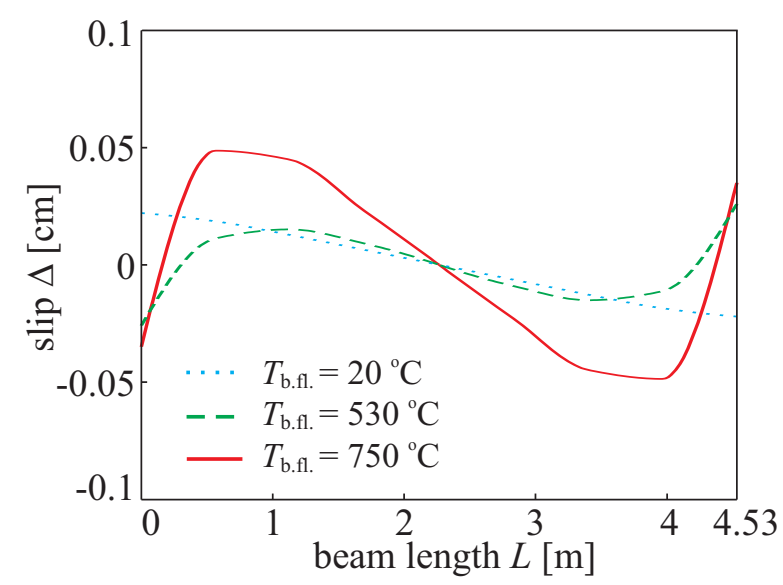

(b) case S2

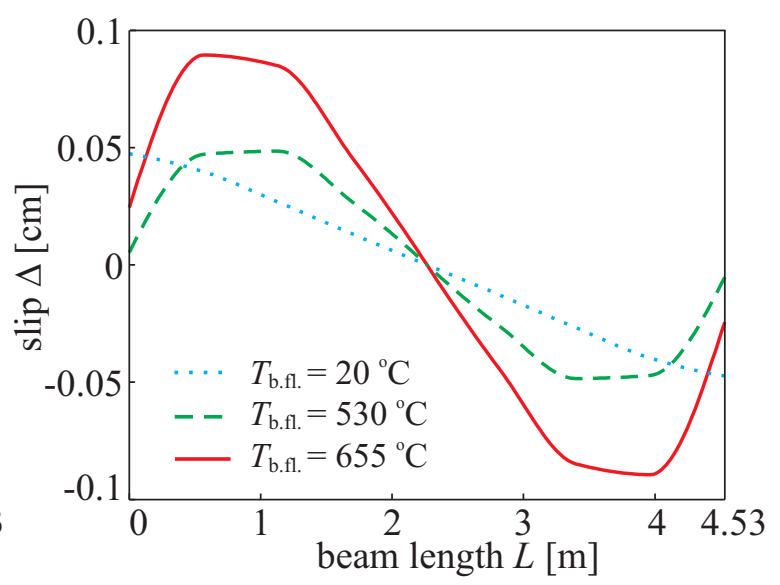

Fig. 8 The variation of slip along the contact. (a) case S1; (b) case S2.

geometry and material assumed in the present composite beam. Slip in case S2 is roughly twice as big as slip in case S1. It must be pointed out that the shape of the slip distribution graph along the beam depends on the temperature. While at room temperature the distribution is nearly linear and maximum slip occurs at the ends of the beam, the location of maximum slip at elevated temperatures is displaced towards inside, the distribution oscillates, and slip is bigger. For example, at $T_{\text {b.fl. }}=530{ }^{\circ} \mathrm{C}$, maximum slip is located at the point roughly $1 \mathrm{~m}$ away from the support. For temperatures higher than $600^{\circ} \mathrm{C}$, the location of the maximum slip again approaches the support; there the sign of slip can even be reversed, see Fig. 8a. In Fig. 9 the tangential traction force along the contact, normalized by the maximum capacity of studs at the current temperature is depicted. As expected, the traction force is in case S2 bigger than in case S1. Fig. 9 shows that the normalized maximal tangential traction force at higher temperatures occurs inside the beam rather than at its ends. The results in Fig. 9 demonstrate that the studs are far from being near the ultimate state. This is further explained by the fact that the studs remain relatively cold (roughly $300^{\circ} \mathrm{C}$ compared to $750{ }^{\circ} \mathrm{C}$ at the bottom of the steel flange, see Fig. 4). Failure of the beam, thus, cannot be atributed solely to studs fracture.

The stress distributions also substantially vary with the increasing temperature. Fig. 10 shows the stress distribution at the midpoint cross-section of the beam at three 
(a) case $\mathrm{S} 1$

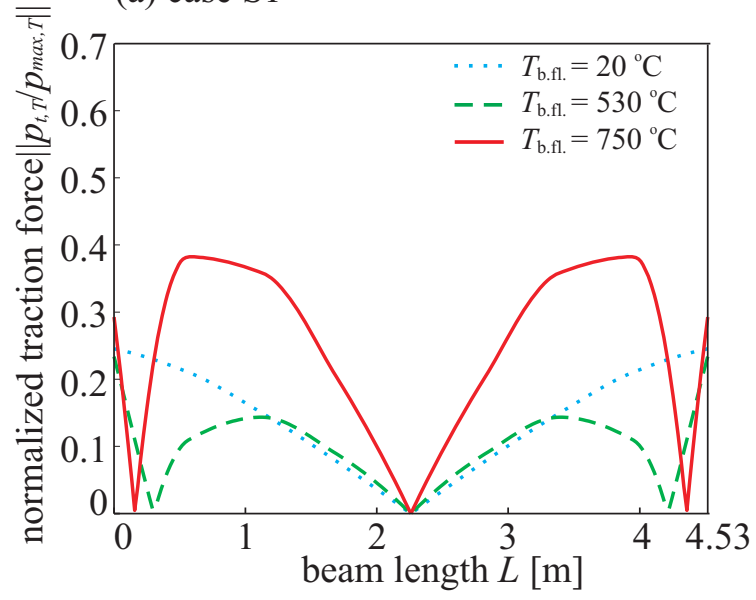

(b) case $\mathrm{S} 2$

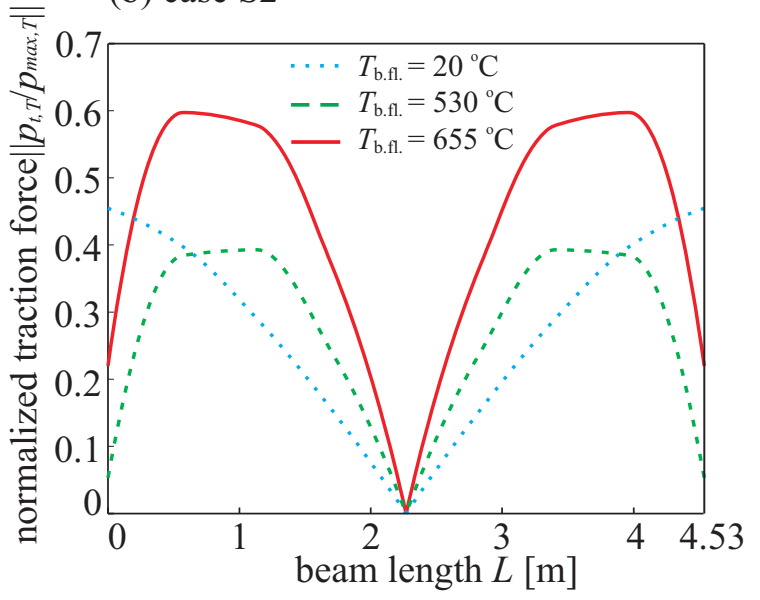

Fig. 9 The variation of normalized tangential traction force along the contact. (a) case S1; (b) case S2.

characteristic stages of fire: at room temperature $\left(20^{\circ} \mathrm{C}\right)$, at $530^{\circ} \mathrm{C}$ at point $\mathrm{A}$ of the bottom flange and close to the critical temperature (at $750^{\circ} \mathrm{C}$ and $655^{\circ} \mathrm{C}$ at point $\mathrm{A}$ for S1 and S2, respectively). The spread of the plastic zone in the steel part of the cross-section is also displayed in the figure. Initially, the whole concrete deck and only a small portion of the steel girder of the composite cross-section undergo compressive stresses. With the initial increase of temperature, the neutral axis of the steel girder is displaced downwards and the steel starts plastifying. Once the plastic zone in steel starts spreading extensively, the neutral axis of the steel girder moves up again. Shortly before the failure of the composite beam takes place, an almost total steel cross-section is in a nearly constant tension with the maximal stress being somewhat bigger only near the steel-concrete contact. Simultaneously, a small part of concrete deck is in compression. As it can be seen in Fig. 3, the temperature over the steel cross-section decreases from its maximum value in the bottom flange to the smaller value at the upper flange. It is also observed that the largest tension stress in steel during fire is somewhat smaller than that at the room temperature (which is due to the degradation of steel strength at elevated temperature), but the peak stress occurs far away from the lower edge. In contrast, the compression stress in steel can be several times bigger than at $20^{\circ} \mathrm{C}$, see Fig. 10a, $T=530^{\circ} \mathrm{C}$, resulting possibly in local buckling of the web, if appropriate 
constructional measures have not been taken. The biggest compression stress in concrete is also substantially bigger in fire, indicating that temperatures in concrete are low. The results in Fig. 10 show that maximum stresses in the steel girder during fire occur in the web of the steel section rather than at the bottom flange, as is expected at room temperature. This is due to a high temperature gradient over the height of the web at some temperature smaller than the critical one (roughly $150^{\circ} \mathrm{C} / 26 \mathrm{~cm}$ ), see Figs. 3 and 4.
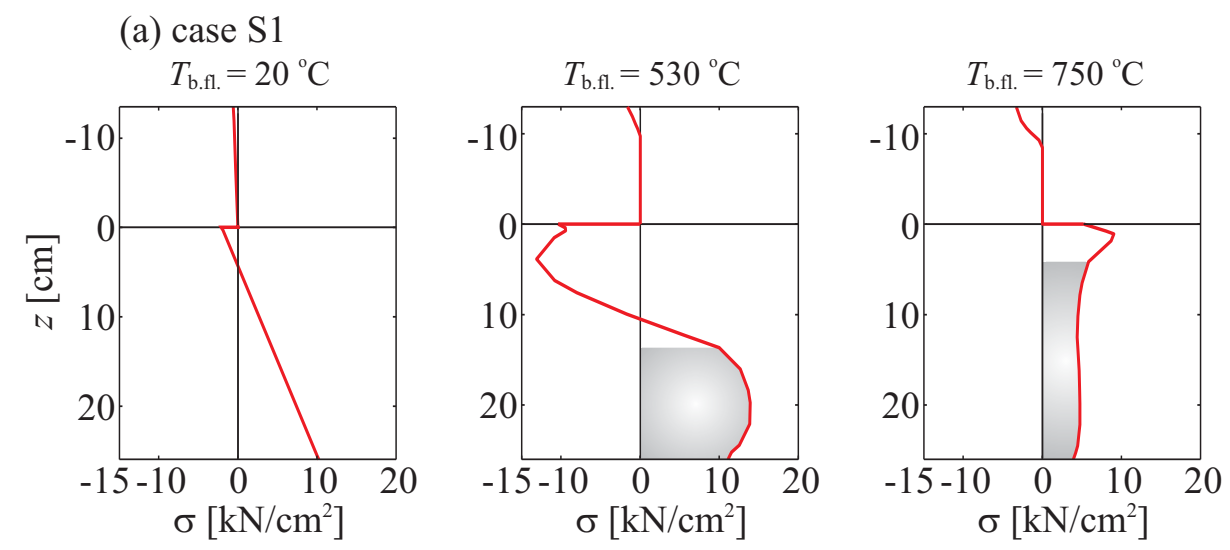

(b) case $\mathrm{S} 2$
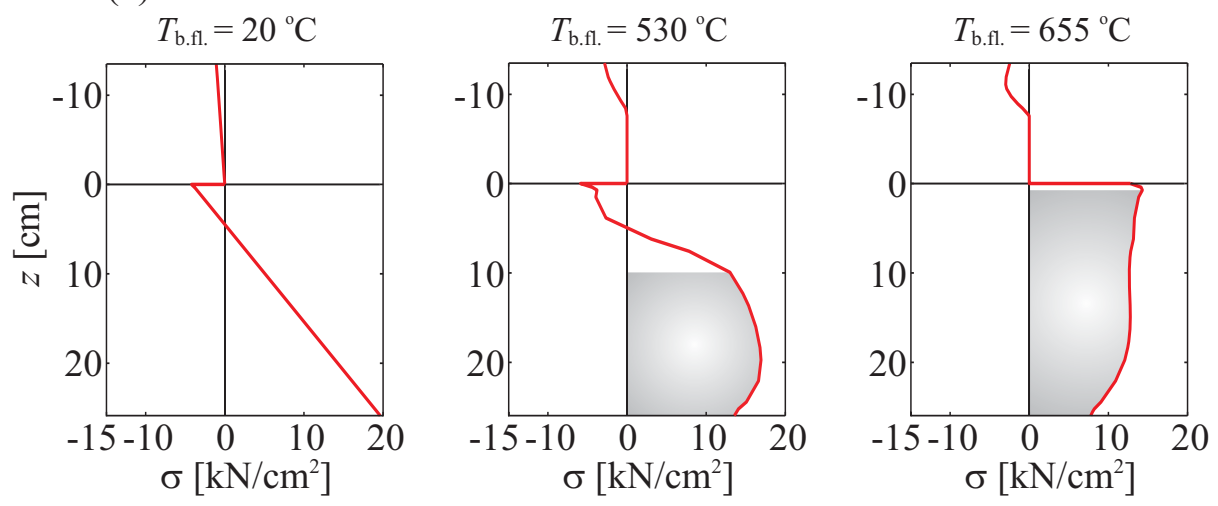

Fig. 10 The distribution of stresses and spread of the plastic zone over the cross-section at the midpoint of the beam. (a) case S1; (b) case S2.

As indicated by the results of the experiment, confirmed by the present numerical results and also pointed out by Huang et al. [13], the connection between the steel girder and the concrete deck of the composite beam tested in experiment is very stiff leading to a nearly full interaction of the components [12]. In order to assess further the effect of the stiffness of the interconnection on failure of the beam due to fire, we 
performed several additional parametric analyses. First we increased the temperature in the shear studs by requiring that it be equal to the temperature in point $\mathrm{C}$ at the top of the upper flange. The results for the midspan deflection, stresses, the contact traction and the critical time using loading of case S2 are practically insensitive to the increased temperature. This does not come as a surprise, because the failure of the beam again takes place very early after the onset of fire (after about 7 min of fire), so that the temperature of the studs has only a short time to grow (to about $400^{\circ} \mathrm{C}$ ) resulting in the stiffness of the contact being changed only a little. Again the studs are stressed far from their ultimate capacity and could not trigger the composite beam failure. To find out if much weaker studs may be the principal reason of the failure, we assume a very weak interconnection having only $25 \%$ of the original bearing capacity at room temperature, i.e. $p_{t, \max }=1.75 \mathrm{kN} / \mathrm{cm}$. Fig. 11a presents the related results denoted by $\mathrm{S} 3$ for the variation of the midspan deflection with temperature of point $\mathrm{A}$ in the bottom flange. The critical temperature is this time lower indeed (about $590^{\circ} \mathrm{C}$ compared to $650^{\circ} \mathrm{C}$ in $\mathrm{S} 2$ ) as is the critical time (roughly $6 \mathrm{~min}$ compared to $7 \mathrm{~min}$ in S2). Fig. 11b shows the distribution of stresses over the midpoint cross-section of the beam at $530^{\circ} \mathrm{C}$. The compression stresses in steel web are now much higher endangering the web to buckle. Studs are more now much more loaded compared to cases S1 and S2 ; in fact they reach the ultimate bearing state over the major part of the beam and thus represent the principal reason of the failure of the beam.

The above presented results show that the composite beam of Wainman and Kirby [12] if subject to loading cases S1 or S2 is very vulnerable to fire as its resistance time is only about 7 to 9 min. This demonstrates that creep strains in steel and concrete do not play a significant role in the beam response. Such an example is thus very convenient for validating time independent elasto-plastic material models for use in fire analyses. Practicians would probably like to find the way how improve the fire resistance of the Wainman and Kirby beam [12]. Yet the chalenge of enhancing the fire resistance is outside of the scope of the present study. 
(a)

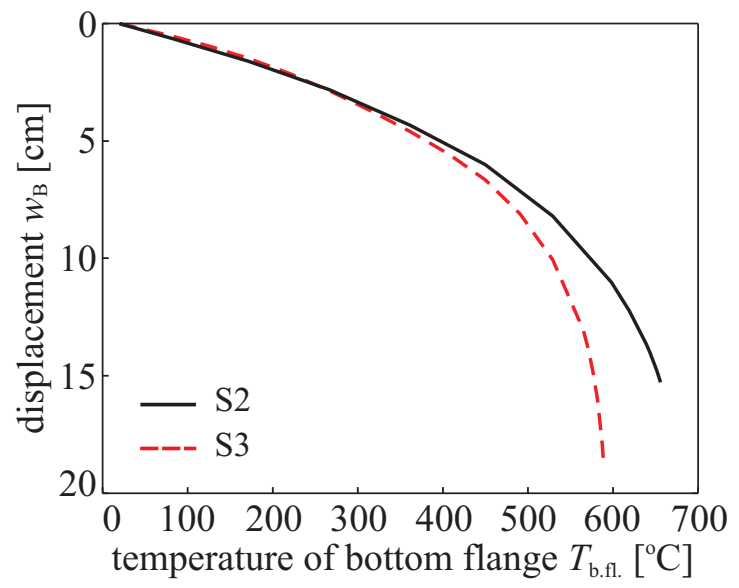

(b)

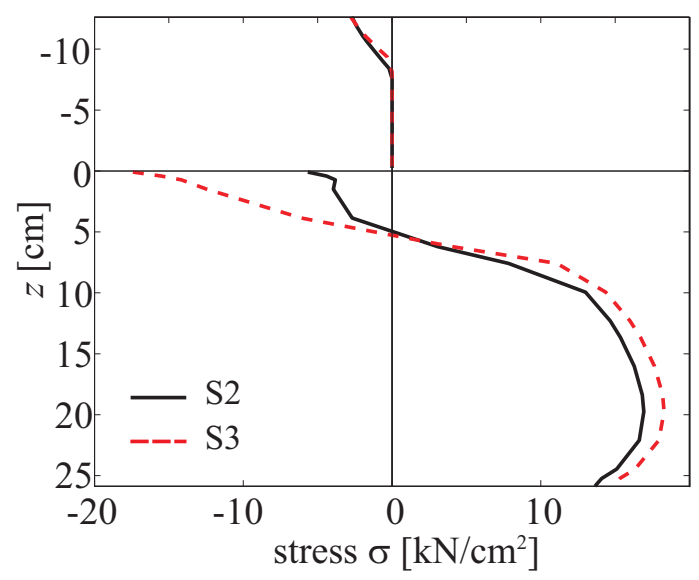

Fig. 11 (a) The variation of the midspan deflection with temperature. (b) The distribution of stresses over the midpoint cross-section.

\section{Conclusions}

The present paper discusses the effects of slip and moisture transfer on the mechanical behaviour of a planar steel-concrete composite beam subject to fire conditions. The moisture and heat transfer during fire is assumed to be governed by the model of Tenchev et al. [5], while the mechanical behaviour accounting for slip between the steel and concrete layers is described by the recent model of the authors $[2,16,17]$. Because the moisture and heat transfer through concrete in fire is slow and the volumetric compressibility of water phase in concrete is much higher than the volumetric compressibility of concrete and thus the relative volume change of pore space cannot produce significant pressures in water [11], it is considered independent of the mechanical deformation, so that the hygro-thermo-mechanical analysis of the composite beam is perfomed in two separate steps, of which the moisture and heat transfer analysis step is performed first, followed by the mechanical analysis of stresses and deformations, based on the moisture and heat transfer results. In solving numerically the governing equations of the problem, we implement the traditional finite element method for the moisture and heat transfer analysis [5, 31], while a novel, strain-based finite element formulation of the planar beam is used in the mechanical analysis [17].

We tested the validity of the present numerical model by comparing our numerical 
results with the data of experiment performed by Wainman and Kirby [12] on a composite, steel-concrete simply supported beam, and with the numerical results of Huang et al. [13] obtained by their original non-linear analysis procedures. The essential charracteristics of the Wainman and Kirby composite beam are its very short fire-resistant time (less than $10 \mathrm{~min}$ ) and a vey stiff connection between steel and concrete layers. The most important engineering-oriented result obtained here is that, for the particular composite beam under consideration [12], the temperature distributions over the concrete crosssection with time are hardly affected by the pore pressures, i.e. nearly equal results are obtained from a coupled or uncoupled hygro-thermal analyses. The numerical results also indicate that slip in the composite beam of Wainman and Kirby [12] does not affect ductility, stress distribution and the critical time substantially, unless the connection is extra weak.

Finally, the present novel, strain-based finite-element beam formulation proves itself perfect for the thermo-mechanical analysis of frame-like structures, as it is robust, reliable and accurate.

\section{References}

[1] Ranzi G, Bradford MA. Direct stiffness analysis of a composite beam-column element with partial interaction. Comp. Struct. 2007;85(15-16):1206-1214.

[2] Čas B, Bratina S, Saje M, Planinc I. Non-linear analysis of composite steel-concrete beams with incomplete interaction. Steel Comp. Struct. 2004;4(6):489-507.

[3] Fabbrocino G, Manfredi G, Cosenza E. Non-linear analysis of composite beams under positive bending. Comp. Struct. 1999;70(1):77-89.

[4] Oven VA, Burgess IW, Plank RJ, Wali AAA. An analytical model for the analysis of composite beams with partial interaction. Comp. Struct. 1997;62(3):493-504.

[5] Tenchev RT, Li LY, Purkiss JA. Finite element analysis of coupled heat and moisture transfer in concrete, subjected to fire. Num. Heat Transfer Part A 2001;39(7):685710. 
[6] Bažant ZP, Thonguthai W. Pore pressure and drying of concrete at hightemperature. J. Eng. Mech. Division ASCE 1978;104(5):1059-1079.

[7] Davie CT, Pearce CJ, Bićanić N. Coupled heat and moisture transport in concrete at elevated temperatures - Effects of capillary pressure and adsorbed water. Num. Heat Transfer Part A 2006;49:733-763.

[8] Gawin D, Pesavento F, Schrefler BA. Modeling of cementitious materials exposed to isothermal calcium leaching, considering process kinetics and advective water flow. Part 1: Theoretical model. Int. J. Solids Struct. 2008;45(25-26):6221-6240.

[9] Tenchev R, Purnell P. An application of a damage constitutive model to concrete at high temperature and prediction of spalling. Int. J. Solids Struct. 2005;42(26):65506565 .

[10] Yuen RKK, Kwok WK, Lo SM, Liang J. Heat and mass transfer in concrete at elevated temperature. Num. Heat Transfer Part A 2007;51:469-494.

[11] Bažant ZP, Kaplan MF. Concrete at high temperatures: material properties and mathematical models. Longman, Harlow, 1996.

[12] Wainman DE, Kirby BR. Compendium of UK standard fire test data, unprotected structural steel - 1. Ref. No. RS/RSC/S10328/1/87/B. Rotherham (UK): Swinden Laboratories, British Steel Corporation, 1988.

[13] Huang Z, Burgess IW, Plank RJ. The influence of shear connectors on the behaviour of composite steel-framed buildings in fire. J. Const. Steel Res. 1999;51(3):219-237.

[14] Ma ZC, Makelainen P. Parametric temperature-time curves of medium compartment fires for structural design. Fire Saf. J. 2000;34(4):361-375.

[15] Reissner E. On one-dimensional finite-strain beam theory: the plane problem. J. Appl. Math. Physics (ZAMP) 1972;23:795-804.

[16] Čas B, Saje M, Planinc I. Non-linear finite element analysis of composite planar frames with an interlayer slip. Comp. Struct. 2004;82(23-26):1901-1912. 
[17] Hozjan T. Non-linear analysis of composite planar structures exposed to fire. University of Ljubljana, Faculty of Civil and Geodetic Engineering, Ph.D. thesis (in Slovenian), 2009.

[18] Eurocode 2. Design of concrete structures, Part 1.2: Structural fire design. European Committee for Standardization, 2004.

[19] Eurocode 3. Design of steel structures, Part 1.2: Structural fire design. European Committee for Standardization, 2004.

[20] Srpčič S. Calculation of the influence of the fire on steel structures. University of Ljubljana, Faculty of Architecture, and Civil and Geodetic Engineering, Ph.D. thesis (in Slovenian), 1991.

[21] Hozjan T, Turk G, Srpčič S. Fire analysis of steel frames with the use of artificial neural networks. J. Const. Steel Res. 2007;63(10):1396-1403.

[22] Harmathy TZ. Fire Safety Design and Concrete. Longman, London, 1993.

[23] Bratina S, Čas B, Saje M, Planinc I. Numerical modelling of behaviour of reinforced concrete columns in fire and comparison with Eurocode 2. Int. J. Solids Struct. 2005;42(21-22):5715-5733.

[24] Anderberg Y, Thelandersson S. Stress and deformation characteristics of concrete at high temperatures, 2. Experimental investigation and material behaviour model. In: Bulletin 54, Institute of Technology, Lund, Sweden, 1976.

[25] Planinc I, Saje M, Čas B. On the local stability condition in the planar beam finite element. Struct. Eng. Mech. 2001;12(5):507-526.

[26] Reddy JN. Applied functional analysis and variational methods in engineering. Singapore: McGraw-Hill Book Co, 1986.

[27] Bratina S, Saje M, Planinc I. On materially and geometrically non-linear analysis of reinforced concrete planar frames. Int. J. Solids Struct. 2004;41(6):7181-7207. 
[28] ISO-834. Fire resistance tests-elements of building construction. International Standard Organization, Geneva, 1975.

[29] Purkiss JA. Fire safety engineering design of structures, Butterworth-Heinemann, Oxford, 1996.

[30] Saje M, Turk G. Software for calculation of non-linear and non-stationary heat transfer. University of Ljubljana, Faculty of Civil and Geodetic Engineering, 1987.

[31] Gawin D, Pesavento F, Schrefler BA. Modeling of cementitious materials exposed to isothermal calcium leaching, considering process kinetics and advective water flow. Part 2: Numerical solution. Int. J. Solids Struct. 2008;45(25-26):6241-6268. 